\title{
Long-Term Monitoring: An Overview
}

\author{
B. Mesraoua ${ }^{1}$, D. Deleu ${ }^{1,2}$ and H. G. Wieser ${ }^{3}$ \\ ${ }^{1}$ Hamad Hospital, Doha, \\ ${ }^{2}$ Weill Cornell Medical College, Doha, \\ ${ }^{3}$ University of Zurich, \\ 1,2Qatar \\ ${ }^{3}$ Switzerland
}

\section{Introduction}

This chapter consists of two parts. In the first part, we will review the indications for longterm EEG monitoring in the diagnosis and management of epilepsy. This will include the differentiation of seizures and epilepsy, appropriate diagnostic and treatment options, the techniques and methods used in the EEG monitoring (ambulatory - hospital-based noninvasive and invasive video/EEG telemetry), commercially available monitoring systems, and presurgical evaluation of candidates for epilepsy surgery. In the second part, we will focus on the continuous EEG monitoring in the Intensive care unit (ICU). In doing so, we will describe which ICU patients should undergo continuous EEG (cEEG) monitoring; how long such patients should be monitored? We will review the epidemiology of nonconvulsive status epilepticus (NCSE) and the pathological EEG patterns commonly occurring in the critically ill patient, including NCSE and periodic epileptiform discharges (PEDs). We will discuss the methods which enable real time monitoring of seizures, and the adequate treatment of these seizures in a timely fashion. We will also discuss the hypothesis that progressive brain damage is occurring with NCSE or PEDs and also whether ICU patients with "controversial EEG patterns" should receive aggressive treatment. Finally, we discuss the hypothesis that biomarkers, such as neuron- specific enolase (NSE), and magnetic resonance imaging (MRI) techniques (diffusion and perfusion MRI) as well as MRSpectroscopy, allow to detect the EEG patterns which might result from brain damage or are associated with it.

\section{Long-term EEG monitoring in the diagnosis and management of epilepsy}

Long-term Monitoring (LTM) is useful and mandatory in the diagnosis and management of epilepsy in epilepsy surgery centers and Intensive care units (ICU). It is used for differentiating between epilepsy and paroxysmally occurring nonepileptic conditions, for assessing seizure type and frequency, for diagnosing and treatment of status epilepticus, and in noninvasive and invasive video/EEG investigations for epilepsy surgery. The Subcommittee of the International League against Epilepsy (ILAE) recommends use of hospital-based LTM in these conditions. The management of patients with head trauma, stroke, subarachnoid hemorrhage and other cerebrovascular disorders benefit from the continuous monitoring of the EEG. 
Techniques/methods. From the techniques/methods one distinguishes: ambulatory versus hospital-based; and noninvasive versus semi-invasive and invasive video/EEG telemetry.

The ambulatory EEG monitoring uses a small portable EEG recorder which is worn on a waist belt. Recording can thereby be made during regular daytime activities and sleep, in the natural environment (see Figure 3). The EEG recorder records events that can be reviewed later on a special machine in an EEG laboratory. The patient should be asked to keep an account of daily activities, so that they can be related to the EEG recordings made at the time.

In comparison to an inpatient monitoring, ambulatory outpatient monitoring may be less informative because: (a) reduction of medication to provoke seizures may not be safe in an outpatient, (b) faulty electrode contacts cannot quickly be noticed and repaired, (c) the patient may move out of video surveillance, and (d) duration of ambulatory monitoring can be limited by technical constraints.

Video-telemetry uses a video camera linked to an EEG machine. The camera will visually record the behavior of the patient, in particular objective signs and symptoms of the seizure, and at the same time the EEG machine will record the brainwave pattern. Both the video and EEG are stored onto a computer that can be reviewed once the test is finished. The consultant will be able to see any episodes/seizures that the patient may have had, as well as any changes in the EEG at that time. The test is often carried out over a number of days in order to increase the chances of recording habitual and/or all seizure types. Long-term video-EEG monitoring is particularly important in the presurgical evaluation of potential candidates for surgical epilepsy therapy, and in the ICU.

Requirements for LTM in general are that it should be suitable for all patient ages, including neonates, infants, children, and adults. It should be suitable for hard-to-record populations as well, such as children with autism. Superior patient safety is mandatory. The user should be able to view all data in standard clinical EEG as well as customizable montages. The computer system should allow for data sharing and data archiving. The system should use ultra-compact amplifier, integrated software design, digital video integration, and world class customer support. Depending on local clinical and research needs the integration of specific software for research use, e.g., source estimation software, and recordings with 32- to 256-channel (dense array EEG) should be available.

Requirements for EEG analysis are online methods that can be potentially used for records of any duration, with any number of channels, any number of channel groupings (different topologies), and in a variety of situations (ICU, sleep, coma, etc.). The system should display samples of original EEG that represent the long-term EEG along with their temporal distribution. The actual EEG should be presented to the user in a familiar way, so that no new interpretive skills are required, i.e., the method can be employed by anyone familiar with EEG. An undisputed advantage is a simple graphical display allowing a non-EEG specialist to identify abnormal changes, i.e., the emergence of focal changes, bursts or sustained asymmetries, gradual or sudden changes, and cycling of EEG patterns. The quick identification of problems will allow such personnel to contact the EEG specialist for a detailed assessment.

Commercially available LTM System are equipped with special hardware, software, and training items, including an amplifier, acquisition computer, LCD display, net station software for EEG acquisition and physician review. In certain conditions a HydroCel 
Geodesic Sensor Net (HCGSN) may be useful. HCGSN does not require any scalp preparation or abrasion and is suitable for all patient ages. Application times for the spongebased HCGSN range between 5 minutes for 32 channels to 15 minutes for 256 channels.

A digital video system is crucial, as is warranty and support. Equally important are on-site installation and training visit by a support engineer providing reference materials and manuals. Regular training workshops of the staff are usually required and helpful.

A reviev of some commercially available Monitoring Systems is given in Table 1.

\begin{tabular}{|c|c|c|}
\hline AirEEG WEE-1000 & $\begin{array}{l}\text { Nihon Kohden } \\
\text { Corporation }\end{array}$ & $\begin{array}{l}\text { The patient wears a transmitter in a pouch } \\
\text { and an electrode junction box in a shoulder } \\
\text { strap. The transmitter sends up to } 64 \text { channels } \\
\text { of EEG data to one or more receivers that are } \\
\text { connected to an electroencephalograph by } \\
\text { LAN. Wireless is more comfortable. }\end{array}$ \\
\hline $\begin{array}{l}\text { Beehive }{ }^{\circledR} \text { Horizon } \\
\text { - Long-term } \\
\text { Epilepsy } \\
\text { Monitoring } \\
\text { Neurotrac }{ }^{\circledR} \\
\text { Neuromonitoring } \\
\text { Software }\end{array}$ & $\begin{array}{l}\text { Grass } \\
\text { Technologies }\end{array}$ & $\begin{array}{l}\text { Windows-based digital EEG/Video } \\
\text { instrument with complete data acquisition, } \\
\text { recording and review capabilities that are } \\
\text { specialized for epilepsy monitoring } \\
\text { applications. } \\
\text { Neurotrac Neuromonitoring software is } \\
\text { designed for computing and displaying long- } \\
\text { term trends of EEG features during } \\
\text { continuous EEG monitoring in the ICU, or } \\
\text { Seizure Monitoring units. The software } \\
\text { module can be used with acquisition systems } \\
\text { configured with any of Grass Technologies' } \\
\text { amplifiers. The number of EEG channels } \\
\text { recorded is dependent on the amplifiers used, } \\
\text { the electrodes applied to the patient, and the } \\
\text { selected montage. }\end{array}$ \\
\hline $\begin{array}{l}\text { Ceegraph VISION } \\
\text { EEG } \\
\text { Ceegraph VISION } \\
\text { ICU } \\
\text { Ceegraph VISION } \\
\text { LTM }\end{array}$ & $\begin{array}{l}\text { Natus Bio-logic } \\
\text { Systems }\end{array}$ & $\begin{array}{l}\text { This system incorporates the latest } \\
\text { developments in networking, remote } \\
\text { communications and information } \\
\text { management. } \\
\text { Ceegraph VISION is a Windows } ® \text { XP Pro } \\
\text { system that can be expanded to integrate all } \\
\text { EEG needs: epilepsy monitoring, routine EEG, } \\
\text { ambulatory recordings, and ICU monitoring. } \\
\text { Ceegraph VISION ICU is designed to } \\
\text { virtually eliminate the complexities of } \\
\text { recording and interpreting continuous EEG } \\
\text { data used to assess neurological status using } \\
\text { sophisticated EEG analysis software. }\end{array}$ \\
\hline
\end{tabular}

Table 1. Commercially Available Monitoring Systems 


\subsection{Diagnostic yield of LTM in the differential diagnosis between epilepsy and paroxysmally occurring nonepileptic conditions}

Events that may cause diagnostic confusion with epilepsy are (a) Non-epileptic pathophysiological events, such as autonomic disorders, cardiac arrhythmias, drug toxicity, metabolic disorders, migraine, orthostatic hypotension, sleep disorders, valvular heart disease, vasovagal syncope, vestibular disorder, and (b) Non-epileptic psychopathological and psychiatric events, such as anxiety, depression, panic attacks, psychogenic "seizures" and other somatoform disorders, and psychosis.

Approximately $20 \%$ of patients referred to comprehensive epilepsy programs because of medically "refractory" seizures do not have epilepsy. In the study of Benbadis et al [1], 75 patients (30\%) of 251 patients with video EEG monitoring had non-epileptic attacks: 69 without epilepsy and 6 patients combined with epileptic attacks. 61 patients from the 69 patients had so-called "psychogenic" and 8 patients had "other" attacks.

Yogarajah et al. [2] studied the value of the ILAE-recommended use of LTM. All admissions to the Sir William Gowers Unit at the National Society for Epilepsy (an epilepsy tertiary referral unit) in the years 2004 and 2005 were included. In this study LTM was primarily responsible for a change in the diagnosis in $133(58 \%)$ and a refinement of diagnosis in 29 $(13 \%)$ patients. The most common change was in distinguishing epilepsy from non-epileptic attack disorder (NEAD) in $73(55 \%)$ and in distinguishing between focal and generalized epilepsy in 47 (35\%). LTM was particularly helpful in differentiating frontal lobe seizures from generalized seizures and non-epileptic attacks.

Besides the diagnosis of a seizure disorder and the classification of seizure types, the evaluation of precipitating factors and the quantification of seizures is often very important. Surgical localization is another issue and briefly dealt below.

\subsection{LTM in the context of presurgical evaluation of candidates for epilepsy surgery}

LTM in specialized institutions offering epilepsy surgery is often divided into a Phase 1 and Phase 2. Phase 1 is noninvasive. In this early stage of examination, three main questions have to be answered: (1) Is it epilepsy? (2) What type of epilepsy? And (3) Is it pharmacotherapy resistant? Phase 2 consists of semi-invasive, and invasive techniques to pinpoint the area(s) where the seizures originate if pharmacotherapy-resistant epilepsy has been determined. Only when a surgically remediable seizure onset zone is determined,then curative epilepsy surgery can be considered.

Epilepsy surgery includes the categories curative (=causal =resective) and palliative epilepsy surgery. Curative means resection of the primary epileptogenic zone, i.e. resection of the actual and potential seizure onset zone. The goal is postoperative seizure freedom. Types of resections include more or less standardized resections as opposed to tailored resections. Standardized resections include interventions such as the "selective amygdalohippocampectomy" [3-4], anterior temporal lobe resection, and functional hemispherectomy (see Figure 1).

Not infrequently the localization of the seizure onset zone in so-called "eloquent", i.e. indispensable brain area and/or the size of the seizure onset zone prevent its radical therapeutic excision. In such a case the "secondary pacemaker areas" (e.g. "ipsilateral 
discharge amplifiers") may be targeted. For example, in a left posterior neocortical temporal lobe epilepsies with rapid propagation of the discharge into the ipsilateral mesial temporal structures (-which act then as a secondary pacemaker - ) a so-called "palliative hippocampectomy" has sometimes been performed with good results [5]. However, palliative interventions usually cannot provide postoperative seizure freedom, but may
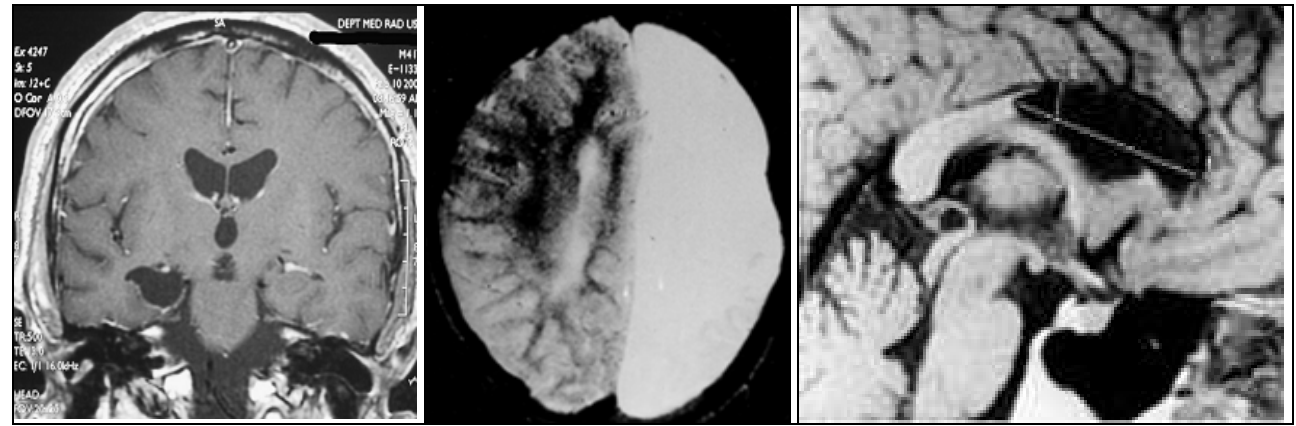

Fig. 1. Illustration of types of resective epilepsy surgery showing the MRI after selective amygdalohippocampectomy (left), after hemispherectomy (middle portion) and after anterior callosal section (right).

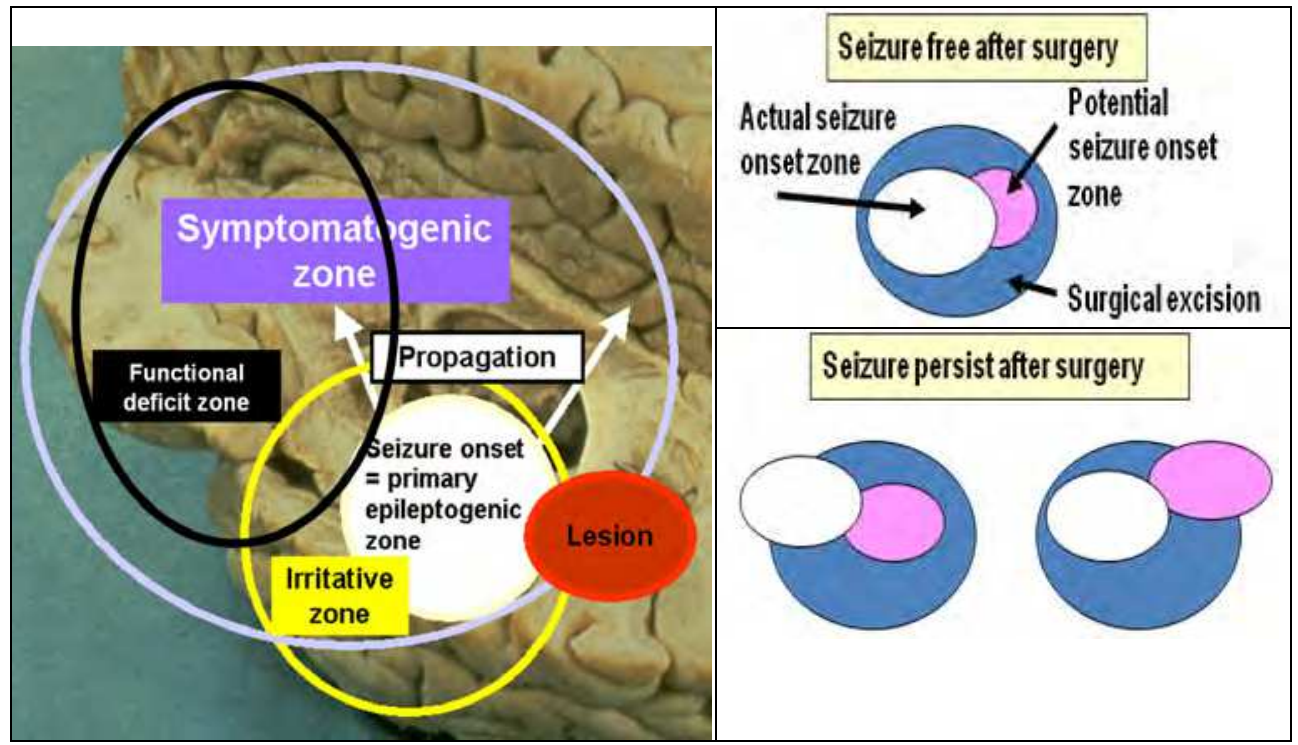

Fig. 2. Illustration of the conceptual zones of the "epileptic" focus. The lesional zone is characterized by the anatomical, i.e. morphological lesion; the irritative zone by the territory exhibiting "interictal spiking". The functional deficit zone is characterized by neurological and/or neuropsychological deficits and/or functional imaging (PET,SPECT) abnormalities; the symptomatogenic zone, by the "primictal", i.e. very early, ictal signs and symptoms. Depending whether the patient is rendered seizure-free or not after surgical excision, the seizure onset zone can be further divided into an actual and potential seizure onset zone. 
ameliorate the patient`s seizure situation. Palliative procedures include callosal section (i.e., corpus callosum section, CCS; including Gamma Knife CCT), vagal nerve stimulation (VNS) and deep brain stimulation (DBS).

Curative epilepsy surgery relies on the concept of the "epileptic focus". At least for practical purposes, the "focus"- concept is still valuable, although the network hypothesis might be more realistic. Using stereo-electroencephalography (SEEG) Talairach and Bancaud have described a "zone lésionelle", a "zone irritative", and a "zone épileptogène" [6]. Wieser [7-8] and Lüders [9] enlarged the focus concept to the following zones (1) lesional (2) primary epileptogenic, (3) secondary epileptogenic (including the "mirror focus", and the "ipsilateral discharge amplifier"), (4) irritative, (5) functional deficit, and (6) symptomatogenic. Lüders et al. [10] then divided the epileptogenic zone into the (a) actual, and (b) potential seizure onset zones, depending whether the patient is rendered seizure-free or not after surgical excision. It is very important to note that the seizure onset zone is not identical with the lesion. Often it is in the vicinity of a lesion, but can be located in or involve remote areas [Figure 2].

Long-term video-EEG monitoring can be performed using conventional scalp electrodes, "true temporal electrodes", sphenoidal electrodes, and in the context of presurgical evaluation the so-called semi-invasive and invasive techniques. Foramen ovale (FO) electrodes are semi-invasive [11]. The so-called invasive techniques include stereo-electroencephalography [12] and subdural strip- and grid electrodes. Not infrequently non-invasive, semi-invasive and invasive techniques are combined with the goal to optimize the diagnostic yield in an individual patient. [8-9,13-14].

Figures 3 to 6 illustrate some aspects of LTM in the context of presurgical evaluation of candidates for epilepsy surgery. Figures 7 to 9 some research aspect, for example the question
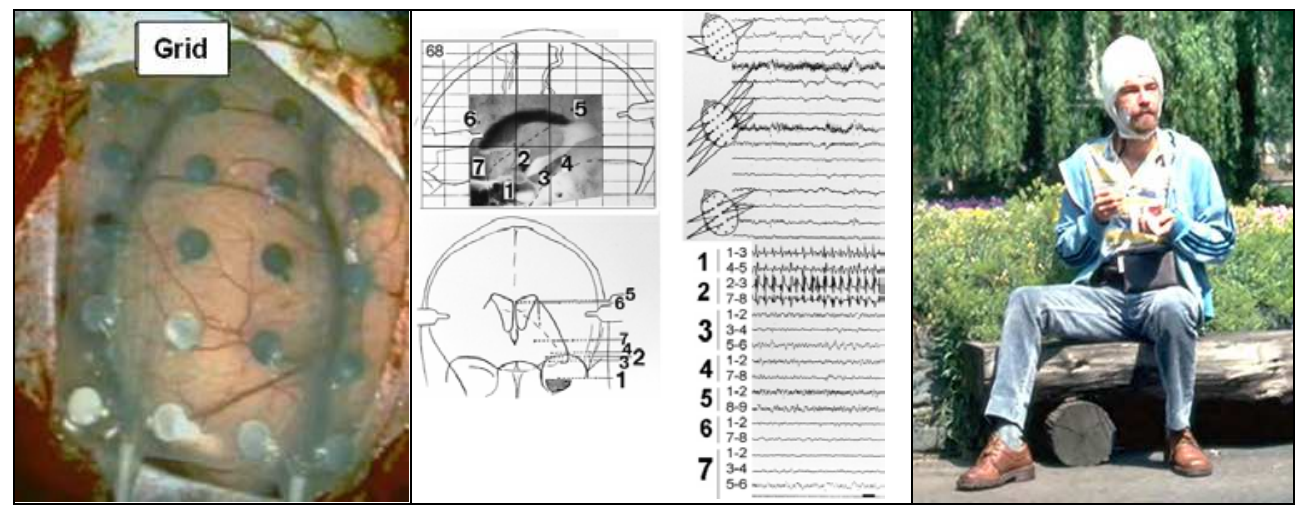

Fig. 3. Placement of a subdural grid during intraoperative electrocorticography (left) and illustration of stereoelectroencephalography (SEEG, middle portion) with a combined scalpand depth-EEG recorded periamygdalar left seizure discharge, not seen in the scalp EEG. The positioning of the 7 depth electrodes (indicated by large and bold numbers) is indicated in the brain map. Each depth electrode has 10 contacts numbered 1 to 10 from inside to outside (small numbers). At the right ambulatory SEEG monitoring is illustrated (University Hospital Zurich 1984). 
of spike activation and seizure precipitation associated with different sleep stages (Figure 8) and seizure prediction (Figure 9). For the latter the pre-ictal spike frequency, the surface negative DC-shift, the inter- and intrahemispheric coupling strength , and some indicators derived from the "chaos theory" (e.g. Lyapunov-exponents and correlation dimension) have been examined. Figure 9 is an example that nonlinear time-series analysis with neuronal complexity loss in interictal EEG recorded with foramen ovale electrodes can predict a seizure. However, in the illustrated case the calculation was done off-line [1516].

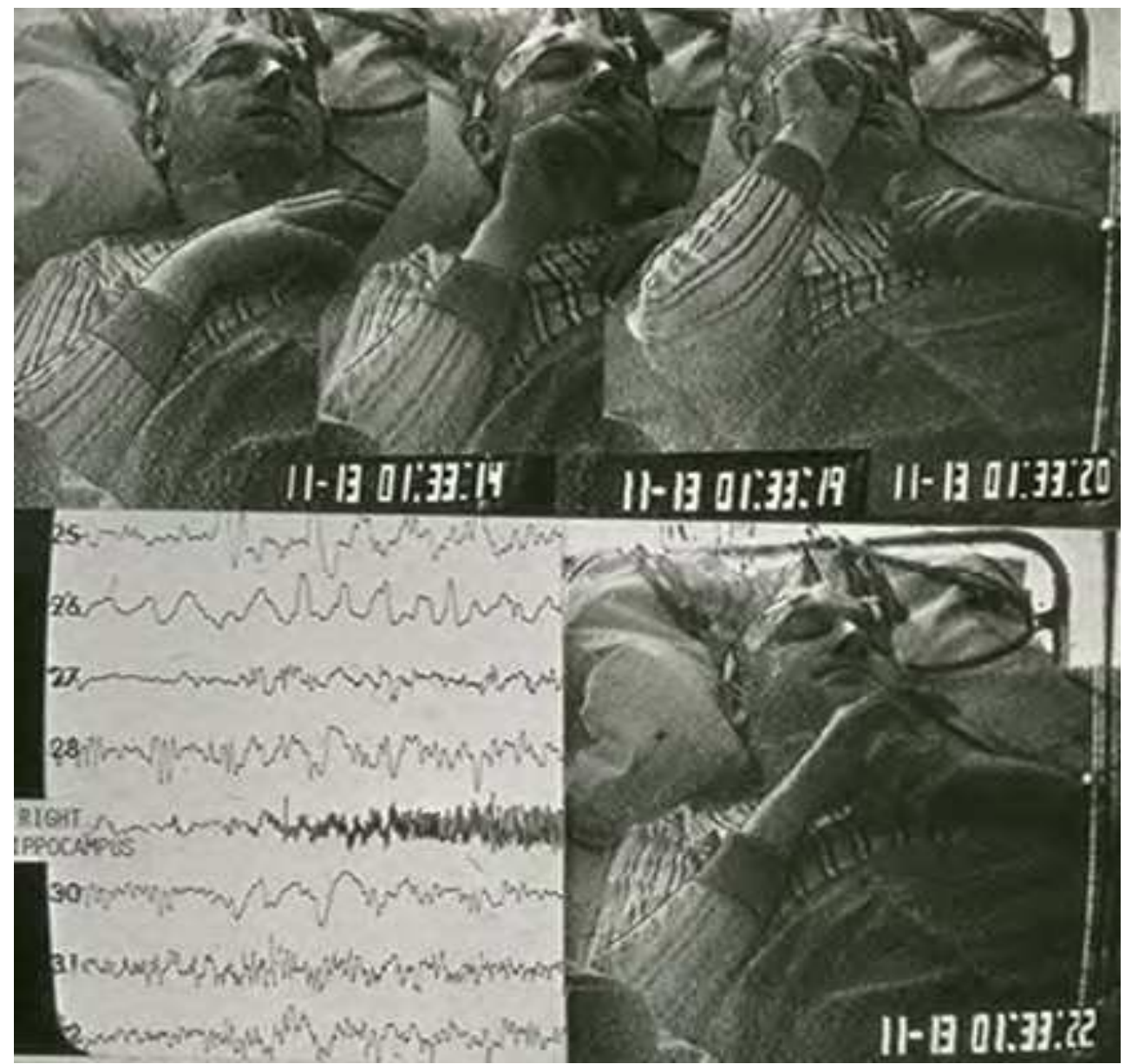

Fig. 4. llustration of invasive video-SEEG monitoring in a patient with pharmacoresistant temporal lobe epilepsy. Depicted is an example of electroclinical seizure analysis: During the right hippocampal high-frequency "tonic" seizure discharge (of 8 seconds, channel 29; the discharge starts at 01:33:14, see left top video-picture) the drowsy patient experienced an olfactory-gustatory aura with ipsilateral nose wiping (modified from Wieser 1983 [7] ). 


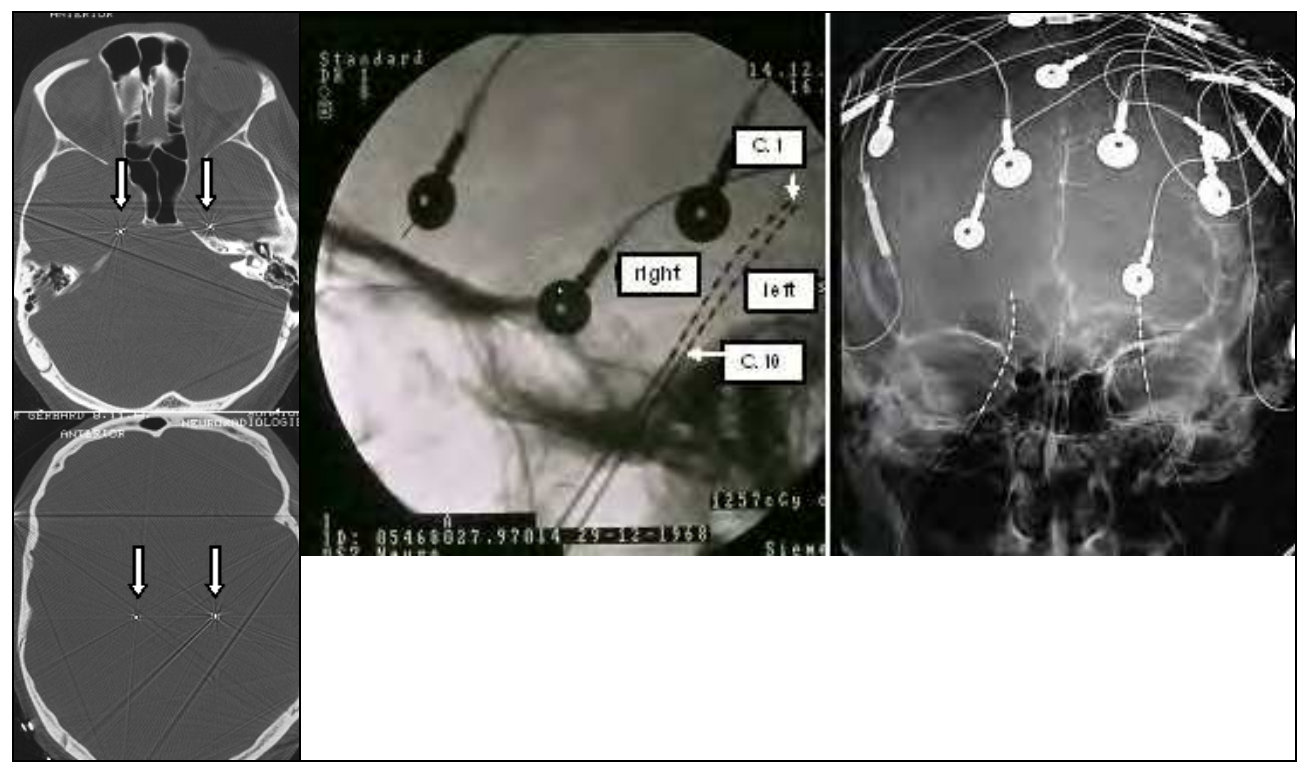

Fig. 5. CT (left) and x-rays with lateral (middle portion) and ap view (right) showing the position of the foramen ovale (FO) electrodes with 10 contacts. Contact 1 is in the ambient cistern and contact 10 close to the foramen ovale.

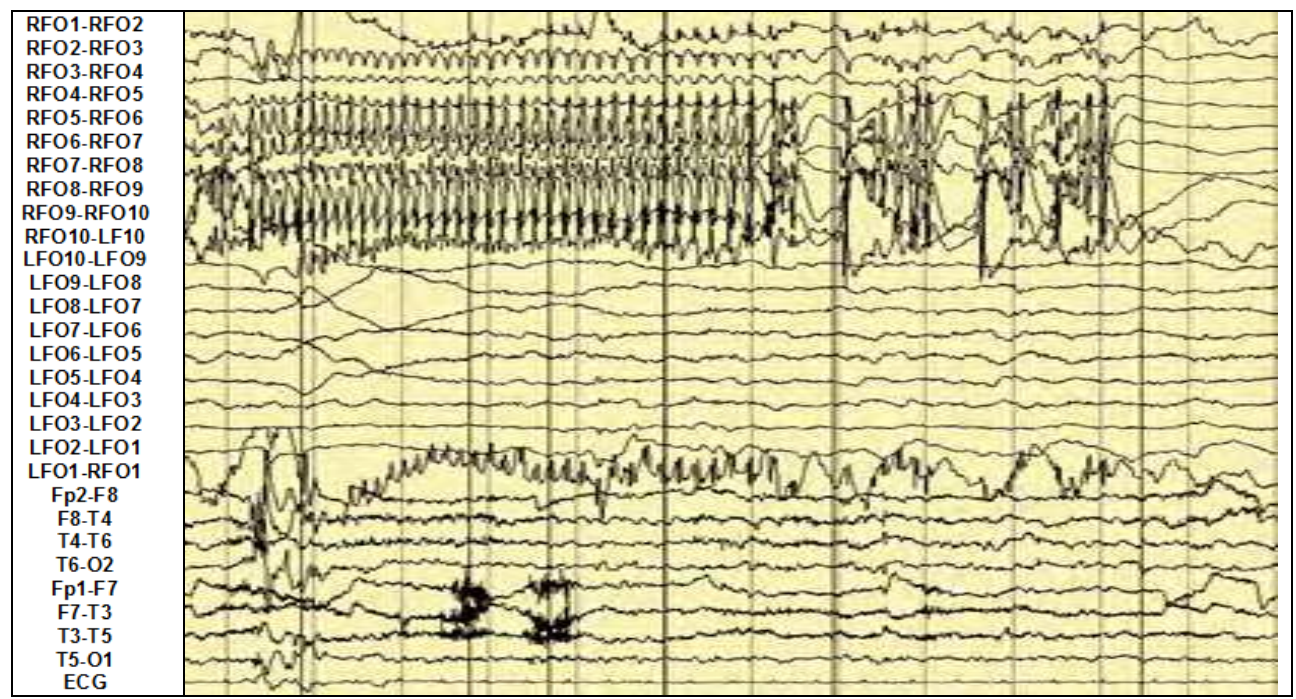

Fig. 6. Illustration of a foramen ovale (FO) recorded right mesiotemporal seizure. Note that the conventional scalp EEG does not reliably pick up this seizure discharge. A total of 12 seconds are shown towards the end of this seizure. Recording from the 10-contact FO electrodes is in a closed chain starting with contact 1 of the right FO electrode (RFO1). R, right; L left. 


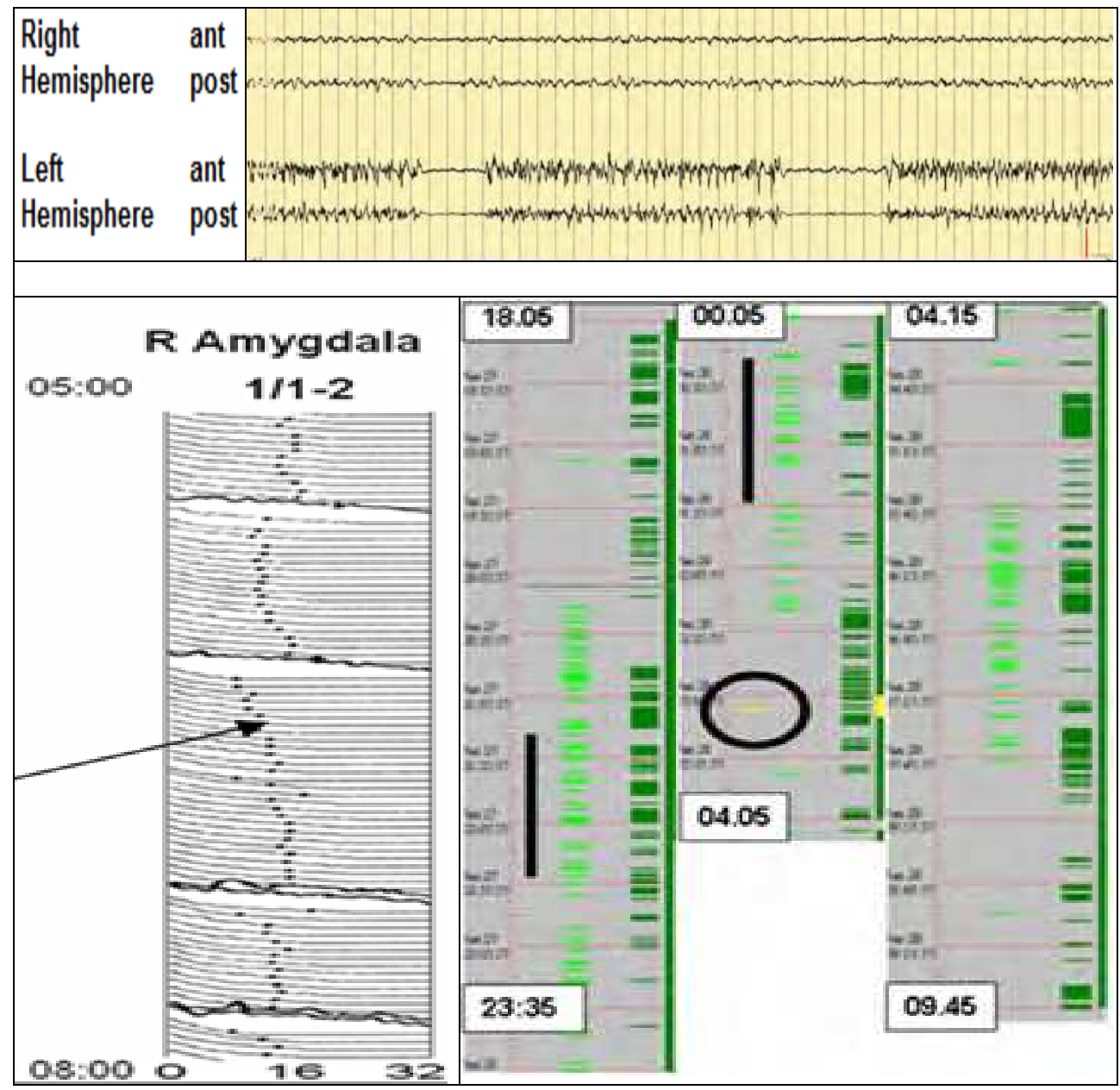

Fig. 7. Top: Example of LTM during an intermittent left hemispheric status epilepticus, showing the actual EEG with seizure discharges of 1.5 - 4 min and intervals of 5 -14 minutes. Bottom left: Graphical display of compressed spectral array over 3 hours (05.00 to 08.00 a.m) showing 4 seizure dicharges in the depth EEG recording from right amygdala. The arrow indicates the spectral edge frequency (SEF) marker set at $97 \%$. Measurement time is 120 msec, power range is -20 to $-60 \mathrm{~d}$. Frequency is from 0 to $32 \mathrm{~Hz}$. Bottom right: Example of the summary display of a surface EEG-LTM (18:05 to 09:45) using the automatic seizure detection Grass-Telefactor TWin 2.60 software. The patient had numerous subclinical seizure discharges (indicated by green bars) and one clinical seizure (indicated by the yellow bar; the circle denotes alarm button press). Quantification of seizure discharges during the black vertical bars revealed more than 20 discharges/hour. 


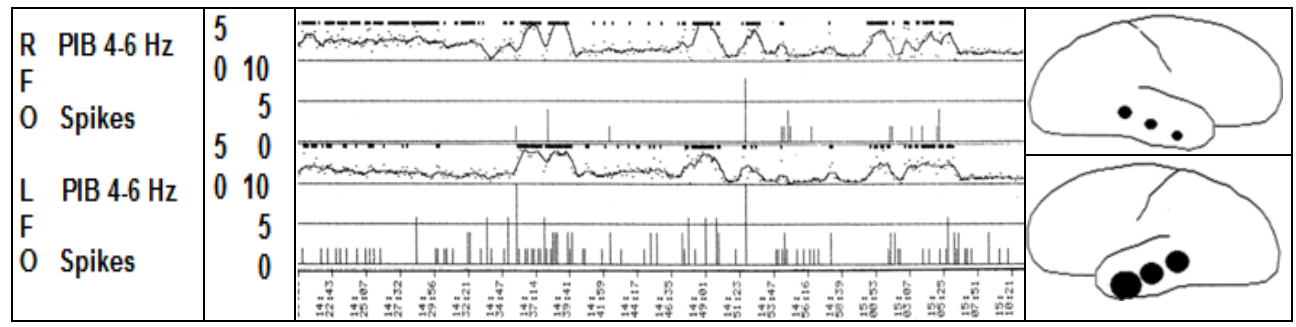

Fig. 8. Chrono-spectrogramm (illustrated are 45 minutes), depicting the vigilance-related activation of spikes using an automatic spike detection algorithm and power in band (BIP) 4-6 $\mathrm{Hz}$ (indicating superficial SWS-sleep). Illustrated are the results of two foramen ovale channels, one right (RFO) and one left (LFO). At the right of the figure a display of quantified FO electrode recorded spikes is shown. There is a marked left anterior mesiotemporal preponderance of spiking. Spiking (measured in units from 0 to 10) is activated during superficial slow-wave-sleep with increase of theta waves (PIB 4-6 Hz is measured in units 0 to 5).

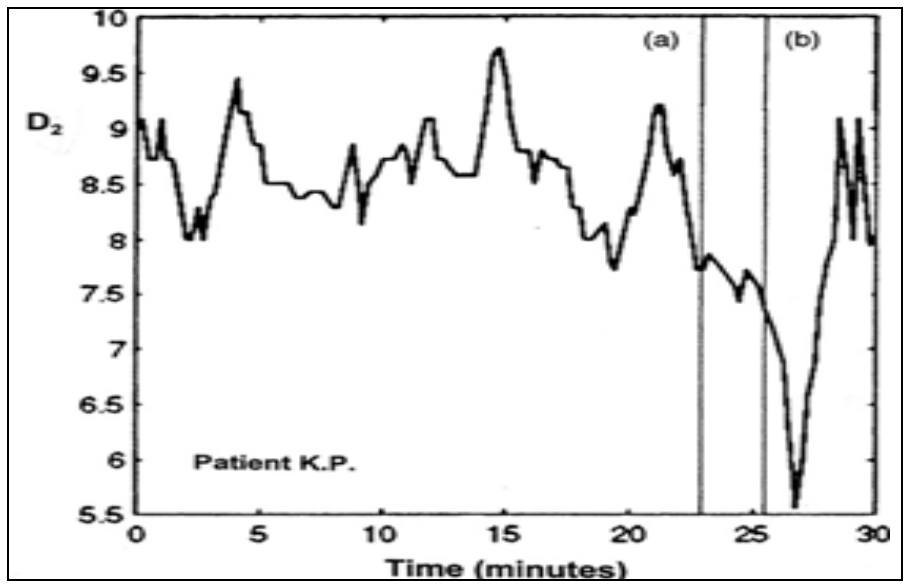

Fig. 9. Seizure prediction: Plot of the correlation dimension D2 over 30 minutes indicating that this measure predicted a seizure about 3 minutes before onset of the foramen ovale recorded seizure discharge. Beginning of the seizure is at the vertical line (b). The D2 transgresses a critical treshold at the vertical line (a). (See also [15 and 16]).

\subsection{LTM in the diagnosis and treatment of status epilepticus}

Continuous EEG (cEEG) monitoring of critically ill patients is frequently utilized to detect non-convulsive seizures (NCS) and non-convulsive status epilepticus (NCSE). Abend et al. [17] studied the current practice of cEEG in critically ill patients. The authors conducted an international survey of neurologists focused on cEEG utilization and NCS management: $83 \%$ of 330 physicians who completed the survey used cEEG at least once per month and $86 \%$ managed NCS at least five times per year. The use of cEEG in patients with altered mental status was common $(69 \%)$, with higher use if the patient had a prior convulsion $(89 \%)$ or abnormal eye movements (85\%). Most respondents would continue cEEG for $24 \mathrm{~h}$. 
If NCS or NCSE was identified, the most common anticonvulsants administered were phenytoin/fosphenytoin, lorazepam, or levetiracetam, with slightly more use of levetiracetam for NCS than NCSE.

\section{Continuous EEG monitoring in the Intensive Care Unit}

In the ICUs, cEEG monitoring reveals the presence of electrographic seizures in a significant percentage of critically ill patients and in patients with depressed levels of consciousness [18-29]. cEEG monitoring is primarily conducted to detect epileptic seizures. It helps assessing the long-term EEG trends and the level of sedation; both essential for treatment and prognosis. Another argument to perform cEEG monitoring in the ICU is costcontainment: In a retrospective study of refractory status epilepticus (RSE) following NCSE (RSE defined as seizures lasting more than 60 minutes and failure of two AEDs), Mayer et al. [30] concluded that it is imperative to diagnose and treat NCS/NCSE as early as possible since the prognosis worsens with increasing duration of seizures which will prolong these patients stay in the ICU and consequently increase the cost on health care ressources.

\subsection{ICU patients that should undergo cEEG monitoring}

NCSE is usually diagnosed when facing a patient with an abnormal mental status and diminished responsiveness, a "compatible" EEG, and frequently a clinical response to antiepileptic therapy. Kaplan [27] asks for both, an alteration in the level of consciousness for 30 to 60 minutes and some seizure activity in the EEG to diagnose NCSE. The EEG remains the most important tool to diagnose NCSE. NCSE can be found in different patient populations, for example in psychiatric and mentally retarded patients on psychotropic medications, and in patients with a history of epilepsy after a tonic-clonic seizure. NCSE/NCSs are common in critically ill patients $[19,21]$. Therefore, we believe that ICU patients with impaired consciousness, especially those patients with unclear etiology, should undergo cEEG monitoring. Clinical conditions where it is appropriate to look for NCSE, are: (a) unexplained diminished level of consciousness (with or without limb and facial twitching and/or eye deviation) in the ICU; (b) confusional states or altered mental status in patients in the emergency room [31]; (c) patients with persisting lethargy or behavioral changes after a tonic-clonic seizure [32], (d) psychomotor retardation or behavioral changes beyong baseline in a psychiatric or mentally retarded patient;

- Lethargy and confusion attributed to a postictal state

- Ictal confusion mistaken for metabolic encephalopathy

- Unresponsiveness and catalepsy presumed to be psychogenic

- Obtundation thought to be due to alcohol or drug intoxication

- Hallucinations and agitation mistaken for psychosis or delirium

- Lethargy presumed secondary to hypoglycemia

- Mutism attributed to aphasia

- Laughing and crying ascribed to emotional lability

Table 2. Clinical examples in which the diagnosis of NCSE was missed or delayed Reproduced from Kaplan PW. Behavioral manifestations of nonconvulsive status epilepticus. Epilepsy and Behavior 2002; 3:122-139 
(e) comatose patients with metabolic / infectious or toxic problems in the ICU [23]; (f) ICU patients in coma with known epilepsy, aged $<18$ years, with a history of convulsive seizures [22]; (g) patients with alteration of level of consciousness after Benzodiazepine withdrawal [33]; (f) patients with drug-induced confusional states such as lithium [34], tiagabine [35] or ifosfamide [36]. Table 2 lists clinical examples in which the diagnosis of NCSE was missed or delayed.

\subsection{Epidemiology of NCSE}

There have been no large-scale population-based studies regarding selectively NCSE. Dunnes et al. [37] estimate that NCSE constitutes $20 \%$ of all status epilepticus in adults. Recent populations-based studies have reported a higher percentage of NCSE among all status epilepticus (30\% to $60 \%$ ) [38-42]. This wide range is explained by the difference in NCSE definition, classification and probably the differences in population characteristics. Knake et al. [40] reported the highest proportion of NCSE in the adult population. Both the large number of patients over 65 years, and the history of stroke and epilepsy might explain this unusually elevated percentage of NCSE in this study. Shorvon [43] reports an annual incidence of NCSE ranging from 5 to 11 per 100,000. Shorvon`s figures are likely underestimates because of the challenges in diagnosing NCSE and also the need for continuous EEG monitoring.

\subsection{Duration of monitoring in the ICU}

There is still no general rule on how long cEEG monitoring should be performed to efficiently detect seizures. Claassen et al. [19] looked for NCSE in comatose patients: in 13\% of these patients, the seizures were recorded during the third day. Unless seizures are recorded during the first few hours, or there is strong suspicion for seizures occurence based on the clinical manifestations and the EEG data or both, we usually record for 24 hours; one example are the periodic discharges (PD). Claassen et al. [19] have shown that the occurence of PD during EEG monitoring is a risk factor for seizures and, in such cases, recording might go beyond 48 hours. Once the seizures are detected and treatment started, EEG monitoring should run uninterrupted from the time continuous IV AEDs is started, until the patient is successfully treated. Frequency of further EEG monitoring depends on the patient's condition; less often EEG recording may be sufficient if the seizures are stopped, while persistent or recurrent seizures require more intensive monitoring.

\subsection{Pathological EEG patterns commonly occurring in the critically ill patient}

A large spectrum of ictal EEG abnormalities may be seen in the ICU, particularly with NCSE [45-46]: Periodic short-interval diffuse discharges (PSIDD) are usually seen in anoxia, metabolic encephalopathy, Creutzfeldt Jakob disease, and toxic encephalopathy (lithium and baclofen). Periodic long-interval diffuse discharges (PLIDD), also called Radermecker complexes, are seen in patients suffering from Subacute Sclerosing Panencephalitis (SSPE) and in patients with Phencyclidine ("angel dust") or ketamine intoxication [47-51]. PLIDDlike patterns are also seen in anoxia and barbiturate intoxication.

The following benign electroencephalographic variants and patterns of uncertain significance may appear during cEEG monitoring but have to be separated from the EEG findings described 
above [47,52]. These patterns include: "Rhythmic temporal Theta bursts of drowsiness [psychomotor variant]", "Midline theta rhythms [formerly Ciganek-rhythm]", "Subclinical rhythmic electrographic discharge in adults [SREDA]", "Wicket spikes", "Small sharp spikes [SSS- previously called Benign epileptiform transients of sleep [BETS]", "14 and $6 \mathrm{~Hz}$ positive bursts" and "6 $\mathrm{Hz}$ spike and wave [also called Phantom spike and wave]".

Generalized periodic burst suppression, generalized periodic slow-wave complexes (GPSC), generalized repetitive sharp transients, and generalized periodic triphasic waves are seen in patients with anoxic/metabolic encephalopathies. GPSC may also occur in subacute sclerosing panencephalitis and in other encephalitis. In comatose patients after cardiorespiratory arrest, burst suppression usually indicates a poor outcome.

Other EEG patterns that are often seen in the ICU are classified according to their predominant EEG frequencies, their morphology or distribution [52]. The following patterns involve mainly the alpha frequencies: Alpha squeak, retained alpha [53], alpha delta sleep [54], unilateral decrease in reactivity of alpha activity and extreme spindles. Beta frequencies include the fast alpha variant, posterior temporal fast activity in children, fast spiky spindle variant, central fast activity, and diffuse paroxysmal or continuous fast activity.The theta frequencies comprise slow alpha variant, frontal arousal rhythm, rhythmic temporal theta activity of drowsiness, middle theta rhythms, and focal parietal theta activity.The delta frequencies include the transient rhythmic slowing occurring after eye closure and more continuous posterior rhythmic slowing . Claassen et al. [19] summarized some EEG patterns seen in the critically ill ICU patient [Table 3]

\begin{tabular}{|l|l|}
\hline Electrographic seizures & $\begin{array}{l}\text { Rhythmic discharge or spike and wave pattern with } \\
\text { definite evolution in frequency, location or morphology, } \\
\text { lasting at least 10s; evolution in amplitude alone does not } \\
\text { qualify }\end{array}$ \\
\hline $\begin{array}{l}\text { Periodic epileptiform } \\
\text { discharges (PEDs) }\end{array}$ & $\begin{array}{l}\text { Repetitive sharp waves, spikes, or sharply contoured waves } \\
\text { at regular or nearly regular intervals and without clear } \\
\text { evolution in frequency or location (includes, PLEDs, } \\
\text { GPEDs, BiPLEDs, triphasic waves) }\end{array}$ \\
\hline $\begin{array}{l}\text { Periodic lateralized } \\
\text { epileptiform discharges } \\
\text { (PLEDs) }\end{array}$ & Consistently lateralized PEDs \\
\hline $\begin{array}{l}\text { Generalized PEDs } \\
\text { (GPEDs) }\end{array}$ & $\begin{array}{l}\text { Bilateral and synchronous PEDs with no consistent } \\
\text { lateralization }\end{array}$ \\
\hline Bilateral PLEDs (BiPLEDs) & $\begin{array}{l}\text { PLEDs occurring bilaterally, but independently and } \\
\text { asynchronously }\end{array}$ \\
\hline Triphasic waves & $\begin{array}{l}\text { Generalized periodic sharp waves or sharply contoured } \\
\text { delta waves with triphasic morphology at 1-3 Hz } \\
\text { with/without anterior-posterior or posterior-anterior lag }\end{array}$ \\
\hline $\begin{array}{l}\text { Frontal intermittent } \\
\text { rhythmic delta activity } \\
\text { (FIRDA) }\end{array}$ & $\begin{array}{l}\text { Moderate to high voltage monorhythmic and sinusoidal 1- } \\
\text { rhythmic delta 3 Hz activity seen bilaterally maximal in } \\
\text { anterior leads, no evolution }\end{array}$ \\
\hline
\end{tabular}

Table 3. Definitions of EEG patterns in ICU seizures given by Claassen [19] 


\subsection{Controversial EEG patterns}

NCSE is accompanied with EEG patterns that are often seen with clinical seizures; however many EEG patterns are called "controversial", because the question whether they are ictal in nature or not, is still debated.

\subsection{Periodic patterns}

These include periodic epileptiform discharges (PEDs) which can be generalized (GPEDs) or lateralized (periodic lateralized epileptiform discharges, PLEDs); or bilateral independent periodic epileptiform discharges (BIPLEDs).

PLEDs are lateralized complexes made up of sharp waves or spikes possibly followed by a slow wave and recurring every one to two seconds [55]. PLEDs are often associated with clinical seizures and also with destructive hemispherical lesions [56]. A great proportion of ICU patients showing these patterns present clinical/electrographic seizures during EEG monitoring [57]. Treiman et al. [58] reported a sequence of five EEG patterns of ictal discharges observed during an untreated generalized convulsive status epilepticus: discrete electrographic seizures, waxing and waning, continuous with flat periods, and PLEDs on a relatively flat background. According to Garzon et al. [59] these patterns should be considered as ictal when they evolve from lower to faster rates $(>2 \mathrm{~Hz})$, change their frequencies, morphology or field (PLEDs-plus). PLEDs are shown in Figure 10.

BIPLEDs are less common than PLEDs; the complexes are asynchronous; their morphology, amplitude, frequency and location generally differ from one hemisphere to the other. They

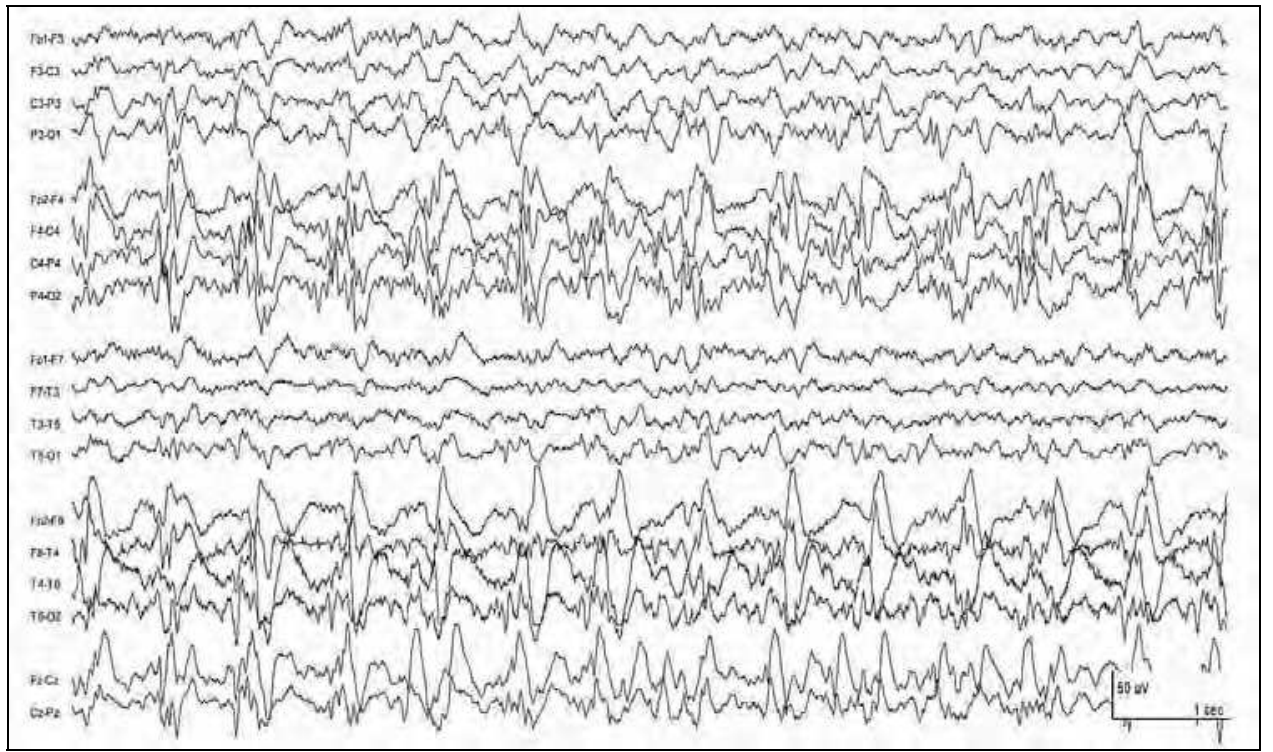

Fig. 10. Periodic lateralized epileptiform discharges (PLEDs) in a 64-year old woman with a right frontal astrocytoma. PLEDs display $1,5 \mathrm{~Hz}$ with intervening fast frequencies (PLEDsplus). PLEDs-plus is extremely likely to evolve into electrographic seizures; whether this pattern represents nonconvulsive status epilepticus is debated. 
are found in hypoxic encephalopathy, encephalitis/meningitis and chronic seizure disorders [60-62]. BIPLEDs are shown in Figure 11.

GPEDs [Figure 12] occur in anoxic-ischemic coma, Creutzfeld-Jacob disease, metabolic encephalopathies, CNS infections such as SSPE, HSV, and in final stages of status epilepticus. GPEDs may represent NCSE [63] or an epileptic encephalopathy [64-65].

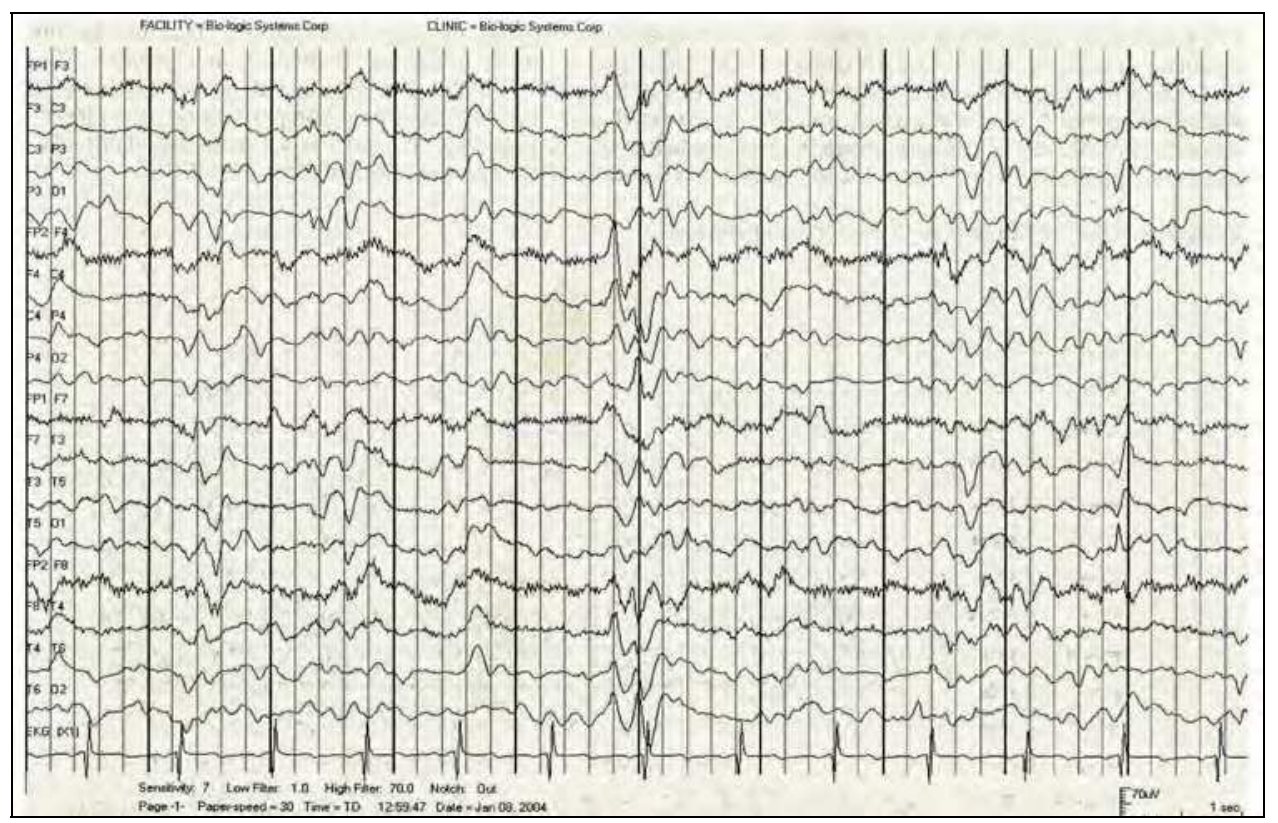

Fig. 11. This EEG shows bilateral independent peudoperiodic lateralized epileptiform discharges in an obtunded patient with left hemisphere complexes every several seconds, independent from right-sided discharges.

\section{Triphasic waves (TWs)}

In NCSE/NCSs, Kaplan [66] describes the TWs as follows: Surface-negative, blunted triphasic complexes with (a) low amplitude, blunted, negative first phase (often widebased); (b) dominant, steep positive second phase, and (c) slow rising third slow-wave component. No polyspike component. Complex duration: 400-600 msec; amplitude: 100 to $300 \mathrm{uV}$ on referential montage; smaller on bipolar. Frequency: 1.0-2.5 Hz (typically $1.8 \mathrm{~Hz}$ ); persistence: wax and wane, but more than $10 \%$ of a standard recording $(20 \mathrm{~min})$. Evolution/reactivity: decrease in sleep, drowsiness or after BZPs; increase and reappear with arousal or noxious stimulation. May exhibit phase-lag best seen on referential montage. TWs may present an epileptiform morphology with spike-like ongoing first phases, and spike-slow-wave complexes. In such cases, it is not easy to differentiate NCSE from metabolic encephalopathy, particularly when TWs run at a frequency exceeding 1 per second. Hence there exist the terms triphasic-like waves and nonepileptic true TWs [63]. Indeed, in NCSE, TWS and generalized spike-wave discharges look similar. In metabolic encephalopathies, in Creutzfeld-Jacob disease, and in the course of status epilepticus, 
bisynchronous periodic sharp complexes with a triphasic configuration are frequently found [58,67-69]. The generalized periodic patterns, associated with lithium, baclofen, ifosfamide, metrizamide, tiagabine, and levodopa, might represent NCSE [70-75]. TWs are also reported in Alzheimer disease [76]. TWs are shown in Figure 13 and "Epileptiform triphasic waves" in Figure 14.

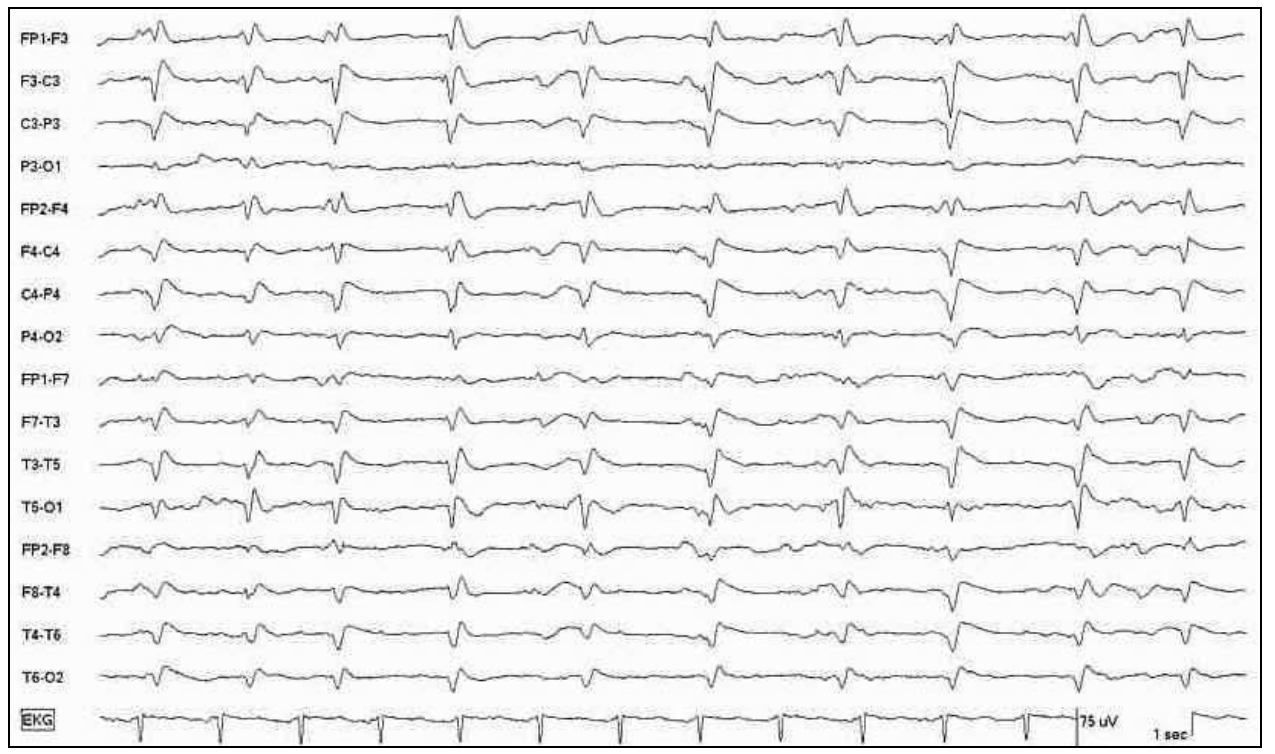

Fig. 12. Generalized periodic epileptiform discharges (GPEDs) in a 45-year-old-man

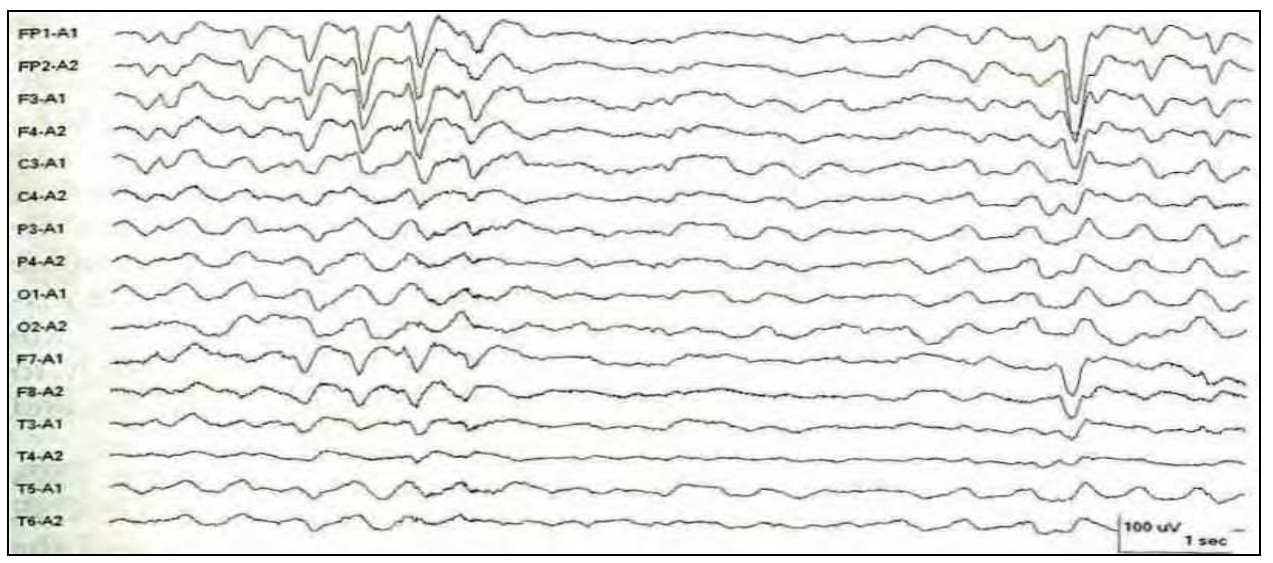

Fig. 13. Triphasic waves in a 51-year-old man with hepatic failure.

SIRPIDs. Stimuli-induced rhythmic periodic, or ictal discharges [SIRPIDs] were first described by Hirsch et al [77]. These are periodic discharges, focal or generalized, frequently seen immediately after stimulation or arousal of a comatose or stuporous patient. SIRPIDs occur 
with acute brain disorders (brain injury) and severe metabolic disorders. Is not clear whether SIRPIDs represent reflex seizures, abnormal arousal patterns, or a combination of both. It has been speculated that faster discharges (more than $3 \mathrm{~Hz}$ ) may be ictal, whereas the slower ones are less likely to be ictal. Few patients have clinical correlates to their SIRPIDs. SIRPIDs are shown in Figure 15.

\subsection{Nonconvulsive status epilepticus in the critically ill ICU patient}

There exists a large literature dealing with classification and electroclinical accompaniments of nonconvulsive status epilepticus (NCSE). NCSE is a heterogenous condition. Its diagnosis is difficult on the basis of clinical semiology alone. An impaired mental status, a reduced responsiveness, a supportive EEG and a response to antiepileptic medications are important criteria to diagnose NCSE. A continuous EEG ictal activity and impaired consciousness for one hour are necessary according to Tomson et al [78]; some form of EEG seizure activity and an impaired consciousness for 30 to 60 minutes according to Kaplan [27]. Because NCSE is not accompanied by generalized jerky movements, cEEG monitoring is essential for detecting nonconvulsive seizures (NCSs)/ NCSE particularly in the ICU [21-29,79]. EEG characteristics of NCSs/NCSE are heterogeneous, with a highly variable morphology; Table 4 describes the EEG patterns occuring in NCSE [25] .

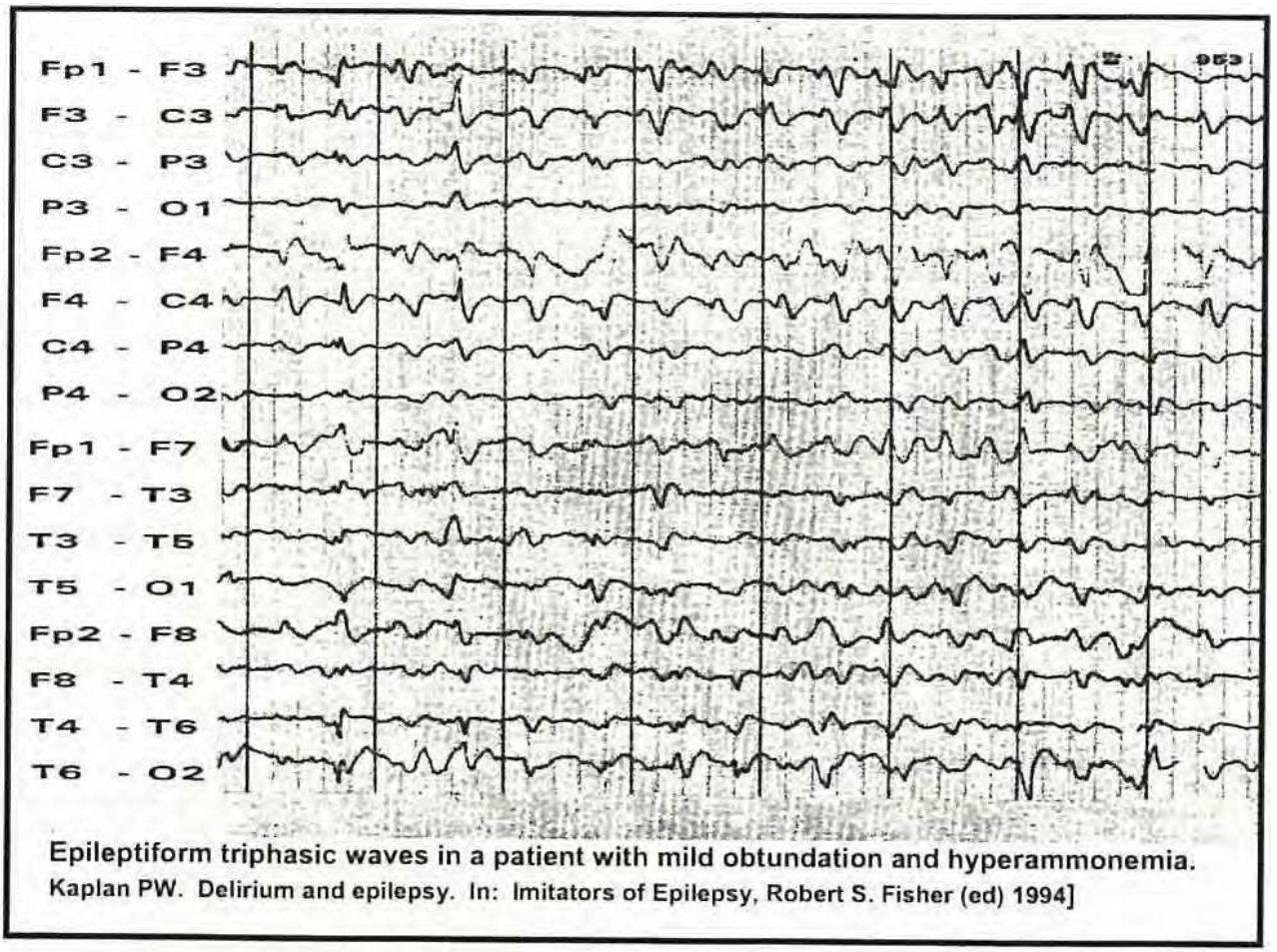

Fig. 14. Epileptiform triphasic waves 
Of particular interest is the distinction between NCSE (as described above) and an epileptic encephalopathy [80]. In this later condition, the impaired level of consciousness is related to the underlying brain pathology causing the seizures rather than the seizures themselves $[22,79,81-83]$.

Although nonconvulsive seizures and NCSE are common in the critically ill patient, many neurologists may be challenged by the frequent "absence" of specific clinical signs, and the difficulty in interpreting the EEG when confronted to such patients. A trial of rapid acting benzodiazepine might be helpful.

Not infrequently NCSE follows a convulsive status epilepticus [32]. In the study of DeLorenzo et al [32], using cEEG recording after the control of convulsive status epilepticus, in 164 patients, the authors found that $48 \%$ showed persistent electrographic seizures, with NCSE in $14 \%$ of them. The authors concluded that the use of cEEG monitoring in these patients was essential in detecting NCSE. Figure 16 shows an example of NCSE.

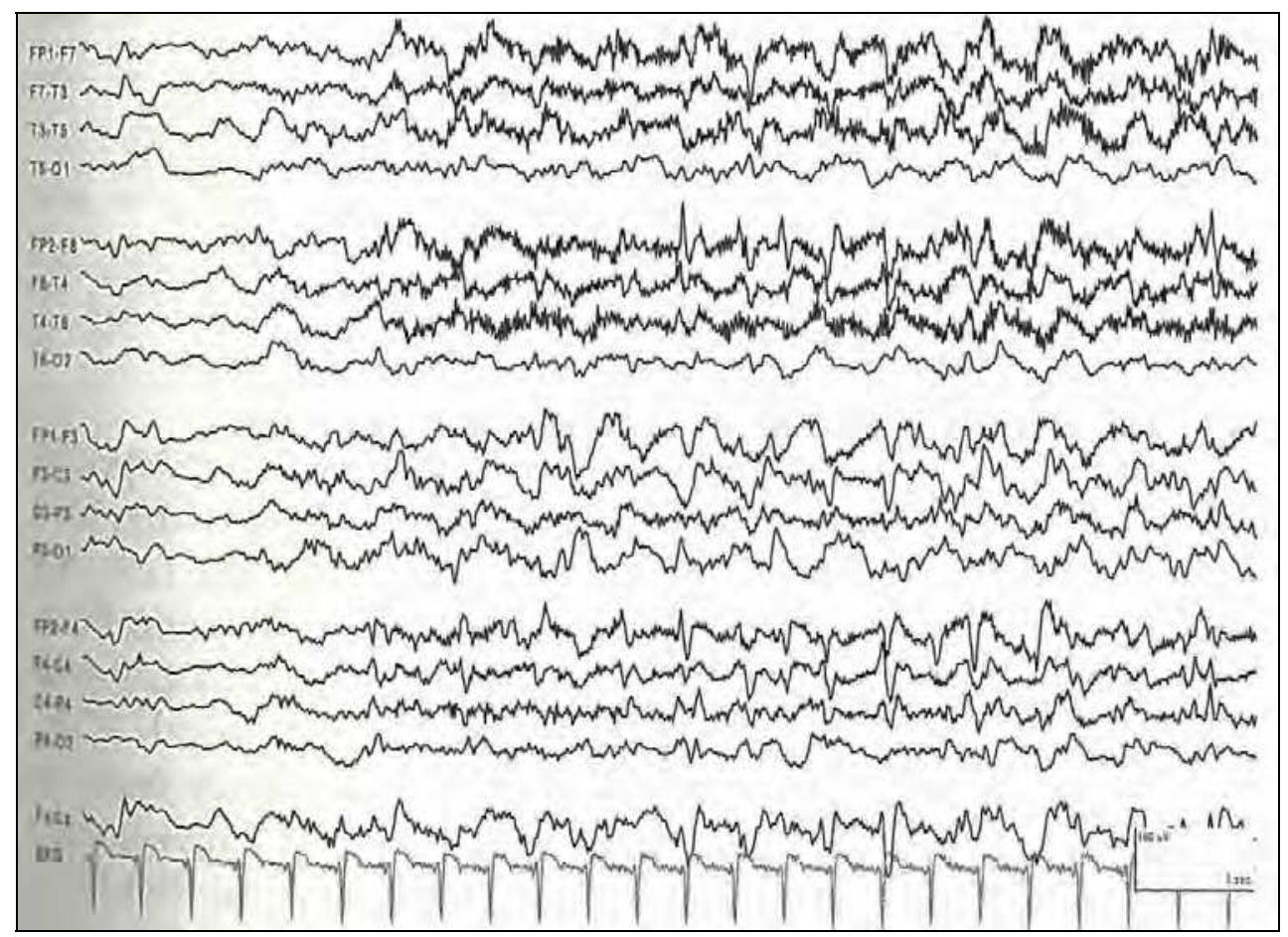

Fig. 15. Stimulus-induced rhythmic periodic or ictal discharges (SIRPIDs). Repetitive right-hemispheric spikes at $2 \mathrm{~Hz}$ were provoked by sternal rub in a patient with subarachnoid hemorrhage.There is simultaneous semi-rhythmic delta activity over the left hemisphere. Electromyographic artifacts indicate a probable change in the patient's state of alertness. 
In patients without a known epileptic encephalopathy

1. Repetitive generalized or focal spikes, poly-spike, sharp waves, spike-and-wave or Spike-and-slow wave complexes at $>2.5$ / second.

2. Above with discharges $<2.5$ / second but with EEG and clinical improvement after rapid onset anti-epileptic drugs, typically benzodazepines (BZPs). [Testing for patient responsiveness and improvement in EEG! EEG: Increases in EEG reactivity and appearance of EEG background activity].

3. Above, with discharges < 2.5/second with focal ictal phenomena (e.g. facial twitching, nystagmus, limb myoclonus).

4. Rhythmic waves (theta-delta) at $>0.5 \mathrm{~Hz}$ with (a) incrementing onset (increase in voltage with increase or decrease in frequency), (b) evolution in pattern (increase or decrease in frequency $(>1 \mathrm{~Hz})$, or location [changes in discharge voltage (amplitude) or morphology are not sufficient], or (c) decrementing termination (voltage or frequency), (d) post-PEDs background slowing or attenuation. (a), (b), (c) or (d) may be acutely induced by IV BZPs.

\section{In patients with known epileptic encephalopathy}

1. Frequent or continuous generalized spike-wave discharges which show an increase in profusion or frequency when compared to baseline EEG with observable change in clinical state

2. Regression (improvement) of clinical or EEG features with BZPs.

Caveat: these are working definitions, exceptions may occur. This classification is not a rote endorsement of the use of parenteral BZPs, which carry clear risk of hypotension and hypopnea. (Classification modified from Kaplan 2005; Young et al. 1996; Hirsh et al. 2005). From Kaplan PW. EEG criteria for nonconvulsive status epilepticus. Epilepsia. 2007; 48 Suppl 8:39-41.

Table 4. EEG patterns suggestive of Nonconvulsive status epilepticus

\subsection{Do NCSE or some EEG patterns (PEDs) damage the brain ?}

PLEDs are often seen with destructive hemispherical lesions and associated with clinical seizures. Baroque \& Purdy assessed 32 patients who had undergone computed tomography (CT) and/or magnetic resonance imaging (MRI). PLEDs and BIPLEDs correlated with postmortem data that showed consistent localization of lesions in the gray matter [56]. Investigators using serial EEG, SPECT, and FDG-positron emission tomography (PET) findings argue that PEDs following SE are often ictal [84]. Others classify PEDs as postictal or simply as markers (an epiphenomenon) of severe injury or encephalopathy. In several studies PLEDS were associated with refractory SE [49]. Jaitly et al [85] reported that ictal discharges which follow GCSE may be harmful. Indeed these discharges are associated with an increase in morbidity and mortality [85]. The mortality in NCSE is similar to that of GCSE. Seizures duration and delay in diagnosis were the factors which correlated the most with mortality rate (33\%) [86]. Claassen et al. [87] reported even a higher mortality rate $(75 \%)$ when NCSE was the first clinical presentation. NCSE could cause long term sequelae from neuronal injury , e.g., impaired cognition or memory loss might result from cortical or hippocampal injury [88].

As mentioned above, NCSE following generalized convulsive status epilepticus is often a refractory status epilepticus and carries a high mortality [32]. Therefore, it is imperative to 
diagnose and treat patients with this condition as early as possible because the prognosis worsens with increasing duration of seizure activity, inducing then more complications and ending with high morbidity and mortality.

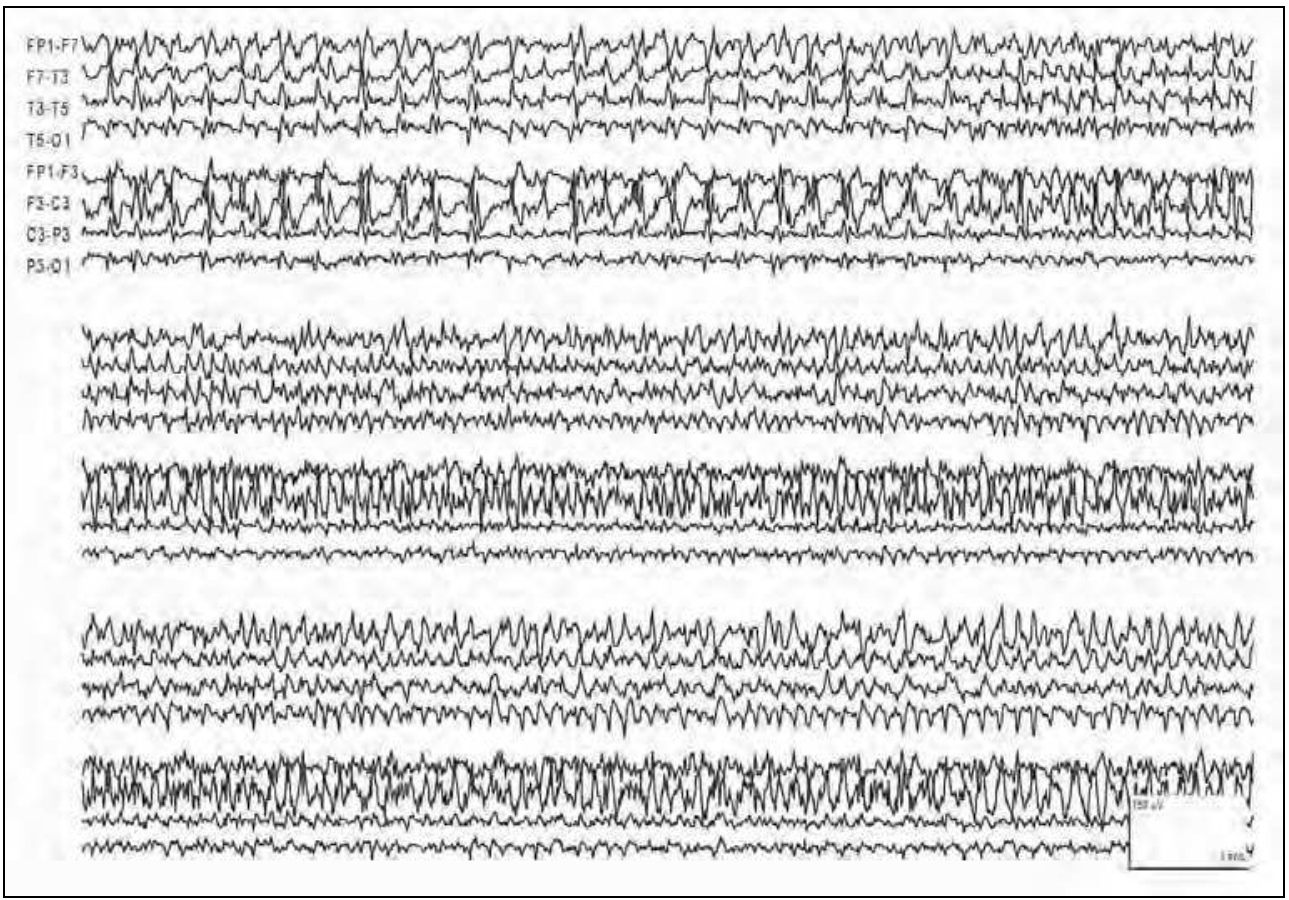

Fig. 16. Nonconvulsive status epilepticus (NCSE) evolving from left-hemisphere periodic lateralized epileptiform discharges (PLEDs) in a 66-year-old man with a left frontal intracerebral hemorrhage. Initially the EEG shows periodic discharges at 1,5 per second, which are invariant for several minutes, then gradually increase in frequency and merge to electrographic theta activity over the entire left hemisphere.This pattern repeated every 5 to 10 minutes for several hours.

There is a strong evidence that the marker of neuronal injury, neuron-specific enolase (NSE) is elevated during NCSE [89-91]. In these studies the level of NSE correlated with the duration of SE favorizing an early treatment of NCSE.

Autopsies of patients with NCSE have shown focal neuronal loss. Three patients, who died 11 to 27 days after the onset of focal motor status epilepticus, but without pre-existing epilepsy, showed neuronal loss and gliosis in the hippocampus, amygdala and periamygdalar area, dorsomedial thalamus, Purkinje cells, pirifrom and entorhinal cortices [92]. The neuronal injury might be responsible for the seizures and NCSE recurrence [93].

In accordance with autopsy studies, nonspecific CT and MRI findings have been reported in NCSE. For example, MRI has shown a transient increased signal in the hippocampus after NCSE [94]. In NCSE, FDG-PET changes are not very consistent, but one reported case showed a focal hypermetabolism which corresponded to the localization of EEG seizure 
activity [95]. The use of SPECT during the seizures ("ictal SPECT") is easier and helpful in localizing the epileptic focus [96].

In humans, the underlying pathophysiology of the various subtypes of NCSE has not been investigated in detail [97-98]. The correlation with underlying pathology, EEG patterns, type of treatment and prognosis remains to be studied. Valid data regarding which EEG patterns cause ongoing neuronal damage are still lacking. Therefore we do not know which patient suffering from NCSE should be treated aggressively. Subtle cases of NCSE may resolve spontaneously. Patients with NCSE with minimal obtundation have a morbidity and mortality of $7 \%$, whereas those with deep lethargy or coma have a mortality rate of 39\%. [86]. Whereas Treiman [99] explicitly recommends that a patient actively having seizures or being comatose and who exhibits any of the periodic epileptiform discharge patterns on EEG should be treated aggressively to stop all clinical and electrical seizure activity to prevent further neurological morbidity and mortality, Kaplan [100] believes that aggressive ICU management of NCSE in the elderly critically ill patient may be harmful rather than beneficial .

\subsection{Future study: To develop a novel cEEG monitoring system able to monitor seizures in real time, and adequately treat these seizures in a timely fashion}

Available seizure-detection software algorithms are geared towards patients with normal EEG backgrounds and high-frequency rhythmic seizure discharges. Unfortunately these computer algorithms are not very successful to detect NCSs/NCSE in ICU patients. This because (a) these kind of seizures have a tendency to wax and wane and do evolve more slowly when compared to the fast activity seen in convulsive seizures, and (b) these seizures are harder to separate from the abnormal background activity related to the impaired vigilance and the associated metabolic disturbances often found in ICU patients [45].

In an ongoing study (Mesraoua et al; see also [101]) we are planning to develop a novel cEEG monitoring system to be used in the ICU. This system should be able to detect pathological EEG patterns commonly occurring in the critically ill patient (NCSE and PEDs, TWs). This system should also be able to quantify the frequency and duration of seizures and will make possible an adequate antiepileptic drug (AED) treatment, in a timely fashion, using the recommended antiepileptic drugs in nonconvulsive seizures/NCSE [102-108]. Using the available neuroradiologic tools (MRIs, MRS) and the CNS biomarkers (Neuronspecific Enolase, NSE), we will examine the possibility that brain damage is occuring with NCSE or PEDs. This way we hope to answer the most important question, i.e., whether NCSE and PEDs should be treated aggressively. This study is a combined effort between neuroscientists/neurologists and signal processing specialists in order to develop a software for the $c E E G$. The technique will use wavelet transforms (WTs) and wavelet packet energy ratio (WPER) which have been proven to be successful tools for epileptic seizure detection, particularly in temporal lobe epilepsy [109-100]. The proposed seizure detection algorithm will perform the following:

1. Subdivide the EEG signal into segments for individual interpretation,

2. Extract features which characterize the individual segments based on EEG behavior in the ICU,

3. Identify the onset of seizures, specifically NCS and NCSE seizures, using the extracted features, 
4. Identify the offset of a seizure, and

5. Provide summaries of the seizure activity over the monitored time frame.

This 3-year research study has just started and no conclusion can be drawn at the present time. Hopefully, cEEG monitoring with the developed algorithm will be able to identify NCSs/NCSE in critically ill patients and thus will help to improve treatment protocols to prevent morbidity.

\section{References}

[1] Benbadis SR. Outcome of prolonged video-EEG monitoring at a typical referral epilepsy center. Epilepsia 2004; 45:1150-3.

[2] Yogarajah M, Powell HW, Heaney D, Smith SJ, Duncan JS, Sisodiya SM. Long term monitoring in refractory epilepsy: the Gowers Unit experience. J Neurol Neurosurg Psychiatry. 2009;80:305-10

[3] Wieser HG, Yasargil MG. Selective amygdalohippocampectomy as a surgical treatment of mesiobasal limbic epilepsy. Surg Neurol 1982:17:445-57

[4] Wieser HG. Selective amygdalohippocampectomy: Indications, investigative technique and results. Advanc Techn Stand Neurosurg. Springer: Vienna 1986; Vol.13:39-133.

[5] Wieser HG. Selective amygdalohippocampectomy has major advantages In: Epilepsy Surgery. Principles and Controversies. Miller JW, Silbergeld DL (eds.) Taylor \& Francis Group: New York 2006:465-78.

[6] Kahane P, Landré E, Minotti L, Francione S, Ryvlin P. The Bancaud and Talairach view on the epileptogenic zone: a working hypothesis. Epileptic Disord. 2006; Suppl 2:S16-26.

[7] Wieser HG. Electroclinical Features of the Psychomotor Seizure. A Stereoelectroencephalographic Study of Ictal Symptoms and Chronotopographical Seizure Patterns Including Clinical Effects of Intracerebral Stimulation. G. FischerButterworths: Stuttgart-London 1983 (242 pp).

[8] Wieser HG, Elger CE. Presurgical Evaluation of Epileptics. Basics, Techniques, Implications. Springer: Berlin, Heidelberg, New York 1987 (415 pp)

[9] Lüders HO, Comair YG (eds.) Epilepsy Surgery, 2nd ed. Lippincott Williams \& Wilkins, 2001

[10] Lüders HO, Najm I, Nair D, Widdess-Walsh P, Bingman W. The epileptogenic zone: general principles. Epileptic Disord. 2006;Suppl 2:S1-9.

[11] Wieser HG, Elger CE, Stodieck SRG. The 'Foramen Ovale Electrode': A new recording method for the preoperative evaluation of patients suffering from mesio-basal temporal lobe epilepsy. Electroenceph Clin Neurophysiol 1985;16:314-22.

[12] Wieser HG. Stereoelectroencephalography. In: Presurgical Evaluation of Epileptics. Wieser HG, Elger CE (eds.) Springer: Berlin-Heidelberg-New York 1987:192-204.

[13] Engel J jun (ed) Surgical Treatment of the Epilepsies. 2nd ed. Lippincott Williams \& Wilkins, 1993

[14] Wieser HG. Stereoelectroencephalography and Foramen ovale electrode recording. In: Electroencephalography: Basic Principles, Clinical Applications, and Related Fields. Niedermeyer E, Lopes da Silva F (eds.) Fourth Edition. Williams \& Wilkins: Baltimore 1999:725-40. 
[15] Moser HR, Meier PF, Wieser HG, Weber B. Pre-ictal changes and EEG analyses within the framework of Lyapunov theory. In: Chaos in Brain? Lehnertz K., Arnhold J, Grassberger P, Elger CE (eds.) World Scientific: Singapore: 2000:96-111.

[16] Weber B, Lehnertz K, Elger CE, Wieser HG. Neuronal complexity loss in interictal EEG recorded with foramen ovale electrodes predicts side of primary epileptogenic area in temporal lobe epilepsy: a replication study. Epilepsia. 1998;39:922-7

[17] Abend NS, Dlugos DJ, Hahn CD, Hirsch LJ, Herman ST. Use of EEG monitoring and management of non-convulsive seizures in critically ill patients: a survey of neurologists. Neurocrit Care. 2010;12:382-9.

[18] Pandian JD, Cascino GD, So EL, Manno E, Fulgham JR. Digital videoelectroencephalography monitoring in the neurological-neurosurgical intensive care unit: clinical features and outcome. Arch Neurol 2004; 61:1090-4.

[19] Claassen J, Mayer S, Kowalski G, et al. Detection of electrographic seizures with continuous EEG monitoring in critically ill patients. Neurology 2004;62:1743-8.

[20] Scheuer M. Continuous EEG monitoring in the intensive care unit. Epilepsia 2002; 43 (Suppl 1):114-27.

[21] Hirsch LJ. Continuous EEG monitoring in the intensive care unit: an overview. J Clin Neurophysiol 2004; 21:332-340

[22] Privitera M, Hoffman M, Moore JL, Jester D. EEG detection of non-tonic-clonic status epilepticus in patients with altered consciousness. Epilepsy Res 1994; 18:155-66

[23] Towne AR, Waterhouse EJ, Morton LD et al. Prevalence of nonconvulsive status epilepticus in comatose patients. Neurology 2000; 54:340-5.

[24] Brown A, Garnett L. Persistent non-convulsive status epilepticus after control of convulsive status epilepticus. Epilepsia 1998; 39:833-40.

[25] Kaplan PW. EEG criteria for nonconvulsive status epilepticus. Epilepsia. 2007;48 Suppl 8:39-41.

[26] Vespa PM, Nuwer MR, Nenov V, Ronne-Engstrom H, Hovda DA, Bergsneider M.et al. Increased incidence and impact of nonconvulsive and convulsive seizures after traumatic brain injury as detected by continuous electroencephalographic monitoring.J.Neurosurg. 1999:91:750-60.

[27] Kaplan PW. Nonconvulsive status epilepticus. Seminars in neurology 1996; 16:33-40.

[28] Bottaro FJ, Martinez OA, Pardal MM, Bruetman JE, Reisin RC. Nonconvulsive status epilepticus in the elderly: a case-control study. Epilepsia 2007; 48:966-72.

[29] Jordan KG. Emergency EEG and continuous EEG monitoring in acute ischemic stroke. J Clin Neurophysiol 2004; 21:341-52

[30] Mayer SA, Claassen J, Lokin J, Mendelsohn F, Dennis LJ, Fitzsimmons BF. Refractory status epilepticus: frequency, risk factors, and impact on outcome. Arch Neurol 2002; 59:205-10.

[31] Kaplan PW. Nonconvulsive status epilepticus in the emergency room. Epilepsia 1996;37:643-50

[32] DeLorenzo RJ, Waterhouse EJ, Towne AR, Boggs JG, Ko D, DeLorenzo GA, et al. Persistent nonconvulsive status epilepticus after the control of convulsive status. Epilepsia 1998; 39:833-840.

[33] Thomas P, Lebrun C, Chatel M. De novo absence status epilepticus as a benzodiazepine withdrawal syndrome. Epilepsia 2005, 34, 2:355-8 
[34] Roccatagliata L, Audenino D, Primavera A, Cocito L. Nonconvulsive status epilepticus from accidental lithium ingestion. Am J Emerg Med. 2002;20(6):570-2.

[35] Jette N, Cappell J, Van Passel L, Akman CI. Tiagabine-induced nonconvulsive status in an adolescent without epilepsy. Epilepsy Res. 2007; 73: 1-52.

[36] Primavera A, Audenino D, Cocito L. Ifosfamide encephalopathy and nonconvulsive status epilepticus. Can J Neurol Sci 2002; 29(2): 180-3

[37] Dunnes JW, Summers QA, Stewart-Wynne EG. Non-convulsive status epilepticus : a prospective study in an adult general hospital. Q J Med 1987;62:117-26.

[38] Delorenzo RJ, Pellock JM, Towne AR, Boggs JG. Epidemiology of status epilepticus . J Clin Neurophysiol 1995;12:316-25.

[39] DeLorenzo RJ, Hauser WA,Towne AR,Boggs JG,Pellock JM, Penberthy L, Garnett L,Fortner CA,Ko D. A prospective, population-based epidemiologic study of status epilepticus in Richmond ,Virginia. Neurology 1996;46:1029-35.

[40] Knake S, Rosenow F, Vescovi M, Oertel WH, Mueller HH, Wirbatz A, Katsarou N, Hamer HM. Incidence of status epilepticus in adults in Germany:a prospective, population-based study.Epilepsia 2001;42:714-18.

[41] Coeytaux A, Jallon P, Galobardes B, Morabia A. Incidence of status epilepticus in French-speaking Switzerland (EPISTAR). Neurology 2000;55:693-7.

[42] Vignatelli L, Rinaldi R, Galeoti M, de CP, D'Allessandro R. Epidemiology of status epilepticus in a rural area of northern Italy: a 2-year population-based study. Eur J Neurol 2005;12:897-902.

[43] Shorvon S.The definition, classification and frequency of NCSE. Epileptic Disord 2005;7:255-8

[44] Claassen J, Jette N, Chum F et al: Seizures and periodic discharges after intracerebral hemorrhage. Neurology 2007; 69:1356-65

[45] Drislane FW. Presentation, evaluation, and treatment of nonconvulsive status epilepticus. Epilepsy Behav. 2000; 1:301-14.

[46] Kaplan PW.The clinical features, diagnosis, and prognosis of nonconvulsive status epilepticus. Neurologist. 2005; 11(6):348-61. Review.

[47] Zumsteg D, Hungerbühler HJ, Wieser HG. Atlas of Adult Electroencephalography. Hippocampus-Verlag, Bad Honnef (Germany), 2004

[48] Brenner RP, Schaul N. Periodic EEG patterns: classification, clinical correlation, and pathophysiology. J Clin Neurophysiol. 1990;7:249-67.

[49] Yemisci M, Gurer G, Saygi S, Ciger A. Generalised periodic epileptiform discharges: clinical features, neuroradiological evaluation and prognosis in 37 adult patients. Seizure 2003; 12:465-72.

[50] Fernandez Torre JL, Arce F, Martinez-Martinez M, Gonzalez-Rato J, Infante J,Calleja J. Necrotizing leukoencephalopathy associated with nonconvulsive status epilepticus and periodic short-interval diffuse discharges: a clinicopathological study. Clin EEG Neurosci. 2006; 37:50-3

[51] Radermecker J. Leucoencéphalite subaigu sclérosante avec lésions des ganglions rachidiens et des nerfs. Rev. neurol. 1949; 81:1009-17.

[52] Westmoreland BF, Klass DW. Unusual EEG patterns. J Clin Neurophysiol 1990;7:209-28 
[53] Sauseng P, Klimesch W, Doppelmayr M, Pecherstorfer T, Freunberger R, Hanslmayr S. EEG alpha synchronization and functional coupling during top-down processing in a working memory task. Hum Brain Mapp 2005; 26: 148-55.

[54] Van Hoof E, De Becker P, Lapp C, Cluydts R, De Meirleir K.Defining the occurrence and influence of alpha-delta sleep in chronic fatigue syndrome. Am J Med Sci 2007; 333: 78-84

[55] Chatrian GE, Shaw CM, Leffman H. The significance of periodic lateralized epileptiform discharges in EEG: an electrographic, clinical and pathological study.Electroencephalogr Clin Neurophysiol 1964;17:177-93.

[56] Baroque HG, Purdy P. Lesion localization in periodic lateralized epileptiform discharges: grey or white matter. Epilepsia,1995:36:58-62.

[57] Snodgrass SM, Tsuburaya K, Ajmone Marsan C. Clinical significance of periodic lateralized epileptic discharges: relationship with status epilepticus.J Clin Neurophysiol 1989;6:159-72.

[58] Treiman DM, Walton NY, Kendrick C. A progressive sequence of elctroencephalographic changes during generalized convulsive status epilepticus. Epilepsy Res 1990;5:49-60.

[59] Garzon E, Fernandes RM, Sakamoto AC. Serial EEG during human status epilepticus : evidence for PLEDs as an ictal pattern.Neurology 2001;57:1175-83.

[60] De la Paz, Brenner RP.Bilateral independant periodic lateralized discharges. Clinical significance. Arch Neurol 1981;38:713-5

[61] Walker M, Cros H, Smith S. Nonconvulsive status epilepticus: Epilepsy Research Foundation Workshop Reports.Epileptic Disord 2005;7:253-93.

[62] Treiman DM, Meyers PD, Walton NY, Collins JF, Colling C, Rowan AJ, Hand-forth A, Faught E, Calabrese VP, Uthman BM, Ramsay RE, Mandani MB. A comparison of four treatments for generalized convulsive status epilepticus. Veterans Affairs Status Epilepticus Cooperative study Group.N Eng J Med 1998;339:792-8.

[63] Hussain AM, Mebust KA, Radtke RA. Generalized periodic epileptiform discharges: etiologies, relationship to status epilepticus, and prognosis. J Clin Neurophysiol 1999:16:51-8.

[64] Krumholz A. Epidemiology and evidence for morbidity of nonconvulsive status epilepticus.Clin Neurophysiol 1999;16:314-2.

[65] Niedermeyer E, Ribeiro M. Considerations of nonconvulsive status epilepticus.Clin Electroencephalogr 2000;31:192-5.

[66] Kaplan PW. EEG criteria for nonconvulsive status epilepticus. Epilepsia. 2007; 48 Suppl 8:39-41.

[67] Brenner RP, Schaul N. Periodic EEG patterns: classification, clinical correlation, and pathophysiology. J Clin Neurophysiol 1990;7:249-67.

[68] Yemisci M, Gurer G, Saygi S, Giger A. Generalized periodic epileptiform discharges: clinical features,neuroradiological evaluation and prognosis in 37 adults patients. Seizures 2003;12:465-72

[69] Wieser HG, Schindler K, Zumsteg D. EEG in Creutzfeldt-Jacob disease.Clin Neurophysiol 2006;117:935-51

[70] Hormes JT, Bennaroch EE, Rodriguez M, Klass DW. Periodic sharp waves in baclofeninduced encephalopathy. Arch Neurol 1988;45:814-5 
[71] Neufeld MY.Periodic triphasic waves in levodopa-induced encephalopathy. Neurology 1992;42:444-6.

[72] Kaplan PW, Birbeck G. Lithium-induced confusional states: nonconvulsive status epilepticus or triphasic encephalopathy? Epilepsia 2006;47:2071-4.

[73] Primavera A, Audenino D, Cocito L. Ifosfamide encephalopathy and nonconvulsive status epilepticus. Can J Neurol Sci 2002; 29: 180-3

[74] Drake ME, Erwin CW. Triphasic EEG discharges in metrizamide encephalopathy. J Neurol Neurosurg Psychiatry 1984;47:324-5.

[75] Jette N, Cappell J, Van Passel L, Akman CI. Tiagabine-induced nonconvulsive status epilepticus in an adolescent without epilepsy. Epilepsy Res. 2007; 73:1-52.

[76] Sundaram MB, Blume WT. Triphasic waves: clinical correlates and morphology. Can J Neurol Sci 1987;14:136-40

[77] Hirsch LJ, Claassen J, Mayer SA, Emerson RG. Stimulus-induced rhythmic, periodic, or ictal discharges (SIRPIDs): a common EEG phenomenon in the critically ill. Epilepsia 2004; 45:109-23

[78] Tomson T, Lindbom U, Nilsson BY. Nonconvulsive status in adults : thirty-two consecutive patients from a general hospital population.Epilepsia 1992;33:829-35.

[79] Litt B, Wityk RJ, Hertz SH, Mullen PD, Weis H, Ryan DD, Henry TR. Nonconvulsive status epilepticus in the critically ill elderly. Epilepsia.1998; 39:1194-202

[80] Kaplan PW. Assessing the outcomes in patients with nonconvulsive status epilepticus: nonconvulsive status epilepticus is underdiagnosed, potentally overtreated, and confounded by comorbidity. J Clin Neurophysiol 1999;16:341-52

[81] Krumholtz A, Sung G, Fisher RS, Barry E, Bergey GK, Grattan LM. Complex partial status epilepticus accompanied by serious morbidity and mortality. Neurology 1995; 45:1499-504.

[82] So El, Ruggles Kh, Ahmann PA, Trudeau SK, Weatherford KJ, et al. Clinical significance and outcome of subclinical status epilepticus in adults. J Epilepsy 1995;8:11-5.

[83] Lowenstein DH, Aminoff MJ. Clinical and EEG features of status epilepticus in comatose patients. Neurology 1992;42:100-4

[84] Handforth A, Cheng JT, Mandelkem MA, Treiman DM. Markedly increased mesiotemporal lobe metabolism in a case with PLEDS: further evidence that PLEDs are manifestations of partial status epilepticus. Epilepsia 1994; 35:876-81.

[85] Jaitly R, Sgro JA, Towne AR, Ko D, DeLorenzo RJ. Prognostic value of EEG monitoring after status epilepticus: a prospective adult study. J Clin Neurophysiol. 1997;14:32634

[86] Young GB, Jordan KG, Doig GS. An assessment of nonconvulsive seizures in the intensive care unit using continuous EEG monitoring: an investigation of variables associated with mortality. Neurology 1996;47:83-9.

[87] Claassen J, Hirsch LJ, Emerson RG, Bates JE, Thompson TB, Mayer SA. Continuous EEG monitoring and midazolam infusion for refractory nonconvulsive status epilepticus.Neurology. 2001;57:1036-42

[88] Shneker BF, Fountain NB. Assessment of acute morbidity and mortality in nonconvulsive status epilepticus. Neurology. 2003;61:1066-73.

[89] DeGiorgio CM, Heck CN, Rabinowicz AL, Gott PS, Smith T, Correale J. Serum neuronspecific enolase in the major subtypes of status epilepticus. Neurology 1999; 52:746-9. 
[90] DeGiorgio CM, Correale J, Gott PS, Ginsburg DL, Bracht KA, Smith T. et al. Serum neuron-specific enolase in human status epilepticus. Neurology 1995;45:1134-7.

[91] DeGiorgio CM, Gott PS, Rabinowicz AL, Heck CN, Smith T, Correale J. Neuronspecific enolase, a marker of acute neuronal injury, is increased in complex partial status epilepticus. Epilepsia 1996;37:606-9

[92] Fujikawa DG, Itabashi HH, Wu A, Shinmei SS. Status epilepticus-induced neuronal loss in humans without systemic complications or epilepsy.Epilepsia. 2000;41:981-91

[93] Tomson T, Lindbom U, Nilsson BY. Nonconvulsive status epilepticus in adults: thirty-two consecutive patients from a general hospital population.Epilepsia. 1992;33:829-35.

[94] Bauer J, Stefan H, Huk WJ, Feistel H, Hilz MJ, Brinkmann HG, Druschky KF, Neundörfer B. CT, MRI and SPECT neuroimaging in status epilepticus with simple partial and complex partial seizures: case report. J Neurol. 1989;236:296-9.

[95] Maeda Y, Oguni H, Saitou Y, Mutoh A, Imai K, Osawa M, Fukuyama Y, Hori T, Yamane F, Kubo O, Ishii K, Ishiwata K. Rasmussen syndrome: multifocal spread of inflammation suggested from MRI and PET findings. Epilepsia. 2003; 44 :1118-21

[96] Kutluay E, Beattie J, Passaro EA, Edwards JC, Minecan D, Milling C, Selwa L, Beydoun A. Diagnostic and localizing value of ictal SPECT in patients with nonconvulsive status epilepticus. Epilepsy Behav. 2005;6:212-7

[97] Wieser HG. Aura continua In: Gilman S, editor. MedLink-Neurobase. San Diego: Arbor Publishing, 3rd 2001 ed. [updated Oct 29,2006]

[98] Wieser HG. Dyscognitive focal (psychomotor, complex partial) status epilepticus.In: Gilman S, editor. MedLink-Neurobase. San Diego: Arbor Publishing,3rd 2001 ed.[updated Oct 29,2006]

[99] Treiman DM. Generalized convulsive status epilepticus in the adult. Epilepsia 1993; 34:S2-S11

[100] Kaplan PW. No, some types of nonconvulsive status epilepticus cause little permanent neurologic sequelae (or: "the cure may be worse than the disease"). Neurophysiol Clin. 2000; 30:377-82.

[101] Mesraoua B, Wieser HG. Non-convulsive seizures and non-convulsive status epilepticus monitoring in the intensive care unit. A real need for the Gulf Cooperation Council countries. Neurosciences (Riyadh). 2009;14:323-37

[102] Hirsch LJ, Claassen J. The current state of treatment of status epilepticus. Curr Neurol Neurosci Rep 2002; 2:345-56.

[103] Alldredge BK, Gelb AM, Isaacs SM, Corry MD, Allen F, Ulrich S, Gottwald MD, O'Neil N, Neuhaus JM, Segal MR, Lowenstein DH. A comparison of lorazepam, diazepam, and placebo for the treatment of out-of-hospital status epilepticus. $\mathrm{N}$ Engl J Med. 2001;345:631-7.

[104] Leppik IE, Derivan AT, Homan RW, Walker J, Ramsay RE, Patrick B. Doubleblind study of lorazepam and diazepam in status epilepticus. JAMA 1983; 249:1452-4.

[105] Rossetti AO, Bromfield EB. Levetiracetam in the treatment of status epilepticus in adults: a study of 13 episodes. Eur Neurol.2005; 54:34-8.

[106] Atefy R, Tettenborn B. Nonconvulsive status epilepticus on treatment with levetiracetam. Epilepsy Behav. 2005; 6:613-6.

[107] Patel NC, Landan IR, Levin J, Szaflarski J, Wilner AN. The use of levetiracetam in refractory status epilepticus. Seizure. 2006; 15:137-41. 
[108] Bensalem MK, Fakhoury TA. Topiramate and status epilepticus: report of three cases. Epilepsy Behav.2003; 4:757-60.

[109] Tafreshi R, Dumont G, Gorss D, Ries CR, Puil E, MacLeod BA. Seizure detection by a novel wavelet packet method. Conf Proc IEEE Eng Med Biol Soc 2006; 76: 6141-4.

[110] Khan YU, Gotman J. Wavelet based automatic seizure detection in intracerebral electroencephalogram. Clin Neurophysiol 2003; 114: 898-908. 


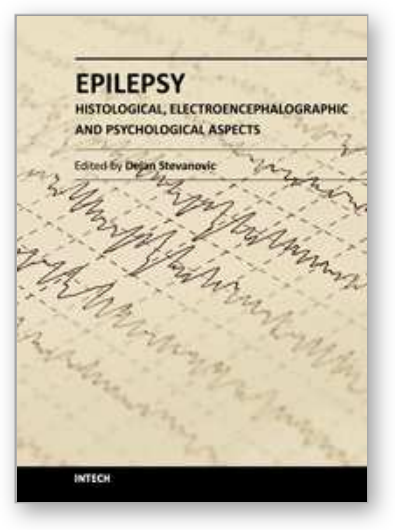

\author{
Epilepsy - Histological, Electroencephalographic and \\ Psychological Aspects \\ Edited by Dr. Dejan Stevanovic
}

ISBN 978-953-51-0082-9

Hard cover, 276 pages

Publisher InTech

Published online 29, February, 2012

Published in print edition February, 2012

With the vision of including authors from different parts of the world, different educational backgrounds, and offering open-access to their published work, InTech proudly presents the latest edited book in epilepsy research, Epilepsy: Histological, electroencephalographic, and psychological aspects. Here are twelve interesting and inspiring chapters dealing with basic molecular and cellular mechanisms underlying epileptic seizures, electroencephalographic findings, and neuropsychological, psychological, and psychiatric aspects of epileptic seizures, but non-epileptic as well.

\title{
How to reference
}

In order to correctly reference this scholarly work, feel free to copy and paste the following:

B. Mesraoua, D. Deleu and H. G. Wieser (2012). Long-Term Monitoring: An Overview, Epilepsy - Histological, Electroencephalographic and Psychological Aspects, Dr. Dejan Stevanovic (Ed.), ISBN: 978-953-51-0082-9, InTech, Available from: http://www.intechopen.com/books/epilepsy-histological-electroencephalographic-andpsychological-aspects/long-term-monitoring-an-overview

\section{INTECH}

open science | open minds

\section{InTech Europe}

University Campus STeP Ri

Slavka Krautzeka 83/A

51000 Rijeka, Croatia

Phone: +385 (51) 770447

Fax: +385 (51) 686166

www.intechopen.com

\section{InTech China}

Unit 405, Office Block, Hotel Equatorial Shanghai

No.65, Yan An Road (West), Shanghai, 200040, China

中国上海市延安西路65号上海国际贵都大饭店办公楼 405 单元

Phone: +86-21-62489820

Fax: +86-21-62489821 
(C) 2012 The Author(s). Licensee IntechOpen. This is an open access article distributed under the terms of the Creative Commons Attribution 3.0 License, which permits unrestricted use, distribution, and reproduction in any medium, provided the original work is properly cited. 